\title{
Extracellular Matrix Degradation and Remodeling in Development and Disease
}

\author{
Pengfei Lu ${ }^{1,2}$, Ken Takai ${ }^{2}$, Valerie M. Weaver ${ }^{3}$, and Zena Werb ${ }^{2}$ \\ ${ }^{1}$ Breakthrough Breast Cancer Research Unit, Paterson Institute for Cancer Research and Wellcome Trust \\ Centre for Cell Matrix Research, Faculty of Life Sciences, University of Manchester, Manchester M20 4BX, \\ United Kingdom \\ ${ }^{2}$ Department of Anatomy and Program in Developmental Biology, University of California, San Francisco, \\ California 94143-0452 \\ ${ }^{3}$ Department of Surgery and Center for Bioengineering and Tissue Regeneration, University of California, \\ San Francisco, California 94143 \\ Correspondence: zena.werb@ucsf.edu
}

\begin{abstract}
The extracellular matrix (ECM) serves diverse functions and is a major component of the cellular microenvironment. The ECM is a highly dynamic structure, constantly undergoing a remodeling process where ECM components are deposited, degraded, or otherwise modified. ECM dynamics are indispensible during restructuring of tissue architecture. ECM remodeling is an important mechanism whereby cell differentiation can be regulated, including processes such as the establishment and maintenance of stem cell niches, branching morphogenesis, angiogenesis, bone remodeling, and wound repair. In contrast, abnormal ECM dynamics lead to deregulated cell proliferation and invasion, failure of cell death, and loss of cell differentiation, resulting in congenital defects and pathological processes including tissue fibrosis and cancer. Understanding the mechanisms of ECM remodeling and its regulation, therefore, is essential for developing new therapeutic interventions for diseases and novel strategies for tissue engineering and regenerative medicine.
\end{abstract}

$\mathrm{T}_{\mathrm{s}=\mathrm{m}}^{\mathrm{h}}$ he extracellular matrix (ECM) forms a milieu surrounding cells that reciprocally influences cellular function to modulate diverse fundamental aspects of cell biology (Hynes 2009). The diversity and sophistication of ECM components and their respective cell surface receptors are among the most salient features during metazoan evolution (Har-el and Tanzer 1993; Hutter et al. 2000; Whittaker et al. 2006; Engler et al. 2009; Huxley-Jones et al. 2009; Ozbek et al. 2010). The ECM is extremely versatile and performs many functions in addition to its structural role. As a major component of the microenvironment of a cell, the ECM takes part in most basic cell behaviors, from cell proliferation, adhesion and migration, to cell differentiation and cell death (Hynes 2009). This pleiotropic aspect of ECM function depends on the highly dynamic structure of ECM and its remodeling as an effective mechanism whereby diverse cellular behaviors can be regulated. This concept is particularly

Editors: Richard O. Hynes and Kenneth M. Yamada

Additional Perspectives on Extracellular Matrix Biology available at www.cshperspectives.org

Copyright (C) 2011 Cold Spring Harbor Laboratory Press; all rights reserved; doi: 10.1101/cshperspect.a005058

Cite this article as Cold Spring Harb Perspect Biol 2011;3:a005058 
P. Lu et al.

important when considering processes and cell behaviors that need to be deployed promptly and transiently and wherein cell-cell and cell-matrix interactions are constantly changing (Daley et al. 2008).

ECM dynamics are a feature of tissues wherein radical remodeling occurs, such as during metamorphosis of insects and amphibians or remodeling of the adult bone and mammary gland, and in developmental processes, including neural crest migration, angiogenesis, tooth and skeletal development, branching morphogenesis, maturation of synapses, and the nervous system (Berardi et al. 2004; Fukumoto and Yamada 2005; Page-McCaw et al. 2007; Zimmermann and Dours-Zimmermann 2008).

ECM dynamics can result from changes of ECM composition, for example, because of altered synthesis or degradation of one or more ECM components, or in architecture because of altered organization. Mounting evidence has shown how individual ECM components are laid down, cross-linked, and organized together via covalent and noncovalent modifications and how they can greatly influence the fundamental aspects of cell behavior (Lopez et al. 2008; Engler et al. 2009; Egeblad et al. 2010b). This higher level of ECM organization is also dynamic and subject to sustained remodeling as mediated by reciprocal interactions between the ECM and its resident cellular components (Daley et al. 2008). Understandably, ECM dynamics are tightly regulated to ensure normal development, physiology, and robustness of organ systems. This is achieved by redundant mechanisms to modulate the expression and function of ECM modifying enzymes at multiple levels. When such control mechanisms are corrupted, ECM dynamics become deregulated, leading to various human congenital defects and diseases, including cancer.

Here, we examine the players involved in ECM remodeling and how they are tightly regulated to achieve a delicate balance between stability and remodeling of the ECM. We focus on the cellular and molecular mechanisms through which ECM dynamics influence cellular behaviors. We illustrate how a wide variety of cell behaviors can be deployed by exploiting the important roles of ECM dynamics to build vertebrate organs and maintain their functions, and how deregulation of ECM dynamics contributes to the initiation and progression of human cancer.

\section{PLAYERS IN ECM DEGRADATION AND REMODELING}

The ECM is composed of a large collection of biochemically and structurally diverse components. Biochemically, these components can be divided into proteins, proteoglycans, and glycoproteins, each of which has diverse subcategories of components and varying physical and biochemical properties. Some of the ECM proteins, including fibrillar collagens and elastin, form fibrils from protein monomers and contribute the major tensile strength and viscoelasticity of the tissue. Other proteins, such as fibronectin, laminin, and nidogen, also participate in building the matrix network as connectors or linking proteins (Vakonakis and Campbell 2007; Daley et al. 2008).

\section{Protein Components of the ECM Are Degraded by Proteinases}

An effective strategy to remodel the ECM is by removal of one or more of its components. This is necessary during profound tissue remodeling processes such as insect and amphibian metamorphosis or mammary gland involution (Sternlicht and Werb 2001). In these cases, massive tissues are replaced by new ones. In most other cases, however, tissue remodeling is much less discernible with spatially restricted cleavage, deposition, or rearrangement of its components (Egeblad and Werb 2002).

All the protein components outside or inside a cell are subject to degradation and modification. The most significant enzymes in ECM remodeling are metalloproteinases (Cawston and Young 2010). Two main families of metalloproteinases, including matrix metalloproteinase (MMP) and a disintegrin and metalloproteinase with thrombospondin motifs (ADAMTS) families, are specialized in 
degrading the ECM. Serine proteinases, which include plasmin and cathepsin $\mathrm{G}$, are active at neutral $\mathrm{pH}$ and also degrade ECM protein components extracellularly. In contrast, cysteine, aspartate, and threonine proteinases are predominantly active at acidic $\mathrm{pH}$ and mainly digest intracellular proteins (Cawston and Young 2010). However, the cysteine proteases cathepsins B and L can be secreted outside the cell and digest the ECM as well (Green and Lund 2005).

There are about 23 members in the MMP family in vertebrates, all sharing a self-inhibitory prodomain at the amino terminus, a catalytic domain, a flexible hinge motif, and a hemopexin domain at the carboxyl terminus (Page-McCaw et al. 2007). Most of the MMPs have the basic three-domain structures, whereas others have certain variations: MMP-2 and MMP-9, for instance, have fibronectin type II repeats inserted in the catalytic domain to mediate collagen binding (Table 1). Although most MMPs are secreted molecules, the membrane-type MMPs (MT-MMPs; MMP$14,-15,-23$, and -24) have a transmembrane domain and a short cytoplasmic tail, whereas MMP-17 and MMP-25 have glycosylphosphatidylinositol (GPI) linkages (Page-McCaw et al. 2007).

MMPs target a wide range of ECM and other extracellular proteins. MMP-3 and -10 , for instance, target proteoglycans, fibronectin, and laminin. Whereas MMP-1 prefers collagen III, MMP- 8 and -13 selectively target collagen I and II, respectively. In addition, both MMP-2 and -9 degrade denatured collagen (gelatin) (Cawston and Young 2010). MMPs are extremely pleiotropic and can perform many functions other than digesting the ECM. Various MMPs can cleave precursor proteins such as pro-MMP precursors and interleukin- 8 and activate them or release cleavage fragments with new bioactivities, such as tumstatin from type IV $\alpha 3$ collagen. Additionally, many MMPs show essential functions unrelated to their proteinase activities (reviewed in Page-McCaw et al. 2007; Kessenbrock et al. 2010).

Like MMPs, ADAMTS proteinases are a multigene family, consisting of 19 members of closely related metalloproteinases (Table 1). As their names indicate, ADAMs and ADAMTSs share several structural domains, including the prodomain, disintegrin domain, which binds to integrins and prevents cell-cell interactions, and the metalloproteinase domain. Unlike ADAMs, however, ADAMTSs do not have a cysteine-rich domain, an epidermal growthfactor-like domain, or a cytoplasmic tail. Instead, ADAMTSs have a thrombospondin type-1 (TSP-1) repeat, a Cys domain, and one or more additional TSP-1 repeats (Apte 2009). As membrane proteins expressed at the cell surface, ADAMs are often involved with cytokine processing and growth factor receptor shedding (Murphy 2008). ADAM-17, for example, can release TNF- $\alpha$ from the cell surface. In contrast, ADAMTSs are mainly responsible for degradation of ECM components, particularly proteoglycans. Indeed, ADAMTS-1, -4, -5, -8, -9, $-15,-16$, and -18 are regarded as proteoglycanases because they can degrade aggrecan, versican, brevican, and other proteoglycans. In contrast, ADAMTS-2 participates in the removal of amino prodomain from procollagen I in the dermis (Apte 2009).

The serine protease plasmin degrades matrix proteins such as fibrin, fibronectin, and laminin, and thus contributes to ECM remodeling (Smith and Marshall 2010). Likewise, neutrophil elastase and cathepsin $\mathrm{G}$ are serine proteases that degrade ECM components (Cawston and Young 2010). These proteases can target essentially all the ECM components and ensure the effective removal of unwanted matrix during a dynamic developmental process and drastic tissue remodeling. Importantly, like MMPs and ADAMTSs, they have many functions, including processing and activating proteinase precursors, besides degrading the ECM (Cawston and Young 2010; Smith and Marshall 2010).

ECM proteoglycans and glycoproteins are also targeted by MMPs and ADAMTSs. Additionally, the various GAG polysaccharide chains can be modified or removed by enzymes that specifically target them, presumably changing ECM function. For example, the extracellular sulfatases SULF1 and SULF2 are extracellular 
P. Lu et al.

Table 1. Properties of the MMP and ADAMTS family members

\begin{tabular}{|c|c|c|c|c|}
\hline Members & Alias & Activators & ECM targets & Other targets \\
\hline \multicolumn{5}{|c|}{ MMPs (23 members) } \\
\hline \multicolumn{5}{|c|}{ Basic domains (prodomain + catalytic domain + hemopexin-containing ancillary domain) } \\
\hline MMP-1 & Collagenase-1 & $\begin{array}{l}\text { MMP-3, -10, } \\
\text { plasmin, } \\
\text { kallikrein, } \\
\text { chymase }\end{array}$ & $\begin{array}{l}\text { Collagens I, II, III, VII, and } \\
\text { X; gelatins; aggrecan; } \\
\text { entactin; tenascin; } \\
\text { perlecan }\end{array}$ & $\begin{array}{l}\text { IGFBP-2, -3, -5; pro-IL-1b; } \\
\text { CTGF; MMP-2, -9 }\end{array}$ \\
\hline MMP-3 & Stromelysin-1 & $\begin{array}{l}\text { Plasmin, } \\
\text { kallikrein, } \\
\text { chymase, } \\
\text { tryptase }\end{array}$ & $\begin{array}{l}\text { Aggrecan; decorin; } \\
\text { gelatins; fibronectin; } \\
\text { laminin; collagens III, } \\
\text { IV, IX, and X; tenascin; } \\
\text { perlecan }\end{array}$ & $\begin{array}{l}\text { IGFBP-3; pro-IL-1b; } \\
\text { HB-EGF; pro-TGF- } \beta \text {; } \\
\text { CTGF; E-cadherin; } \\
\text { plasminogen; uPA; } \\
\text { pro-MMP-1, -7, -8, -9, -13 }\end{array}$ \\
\hline MMP-8 & Collagenase-2 & $\begin{array}{l}\text { MMP-3, }-10 \\
\text { plasmin }\end{array}$ & $\begin{array}{l}\text { Collagens I, II, and III; } \\
\text { gelatins; aggrecan; }\end{array}$ & \\
\hline MMP-10 & Stromelysin-2 & $\begin{array}{l}\text { Plasmin, } \\
\text { kallikrein, } \\
\text { chymase, } \\
\text { tryptase }\end{array}$ & $\begin{array}{l}\text { Aggrecan; fibronectin; } \\
\text { laminin; collagens III, } \\
\text { IV, and V }\end{array}$ & Pro-MMP-1, $-8,-10$ \\
\hline MMP-11 & Stromelysin-3 & Furin, plasmin & $\begin{array}{l}\text { Fibronectin; laminin; } \\
\text { aggrecan; gelatins }\end{array}$ & IGFBP-1 \\
\hline MMP-12 & Metalloelastase & n.d. & $\begin{array}{l}\text { Elastin; aggrecan; } \\
\text { fibronectin; } \\
\text { osteonectin; laminin; } \\
\text { nidogen }\end{array}$ & Plasminogen \\
\hline MMP-13 & Collagenase-3 & $\begin{array}{l}\text { MMP-2, } \\
\text { MMP-14, } \\
\text { plasmin, } \\
\text { kallikrein, } \\
\text { chymase, } \\
\text { tryptase }\end{array}$ & $\begin{array}{l}\text { Collagens I, II, III, IV, IX, } \\
\text { X, and XIV; aggrecan; } \\
\text { fibronectin; tenascin; } \\
\text { SPARC/osteonectin; } \\
\text { laminin; perlecan }\end{array}$ & CTGF; pro-TGF- $\beta$; MCP-3 \\
\hline MMP-21 & XMMP & n.d. & n.d. & n.d. \\
\hline MMP-27 & & n.d. & & n.d. \\
\hline \multicolumn{5}{|c|}{ Minimal domains (prodomain + catalytic domain) } \\
\hline MMP-7 & Matrilysin-1 & $\begin{array}{l}\text { MMP-3, }-10 \\
\text { plasmin }\end{array}$ & $\begin{array}{l}\text { Aggrecan; gelatins; } \\
\text { fibronectin; laminin; } \\
\text { elastin; entactin; } \\
\text { collagen IV; tenascin; } \\
\text { decorin }\end{array}$ & $\begin{array}{l}\beta 4 \text { integrin; E-cadherin; } \\
\text { pro-TNFa; CTGF; } \\
\text { HB-EGF; RANKL; } \\
\text { IGFBP-3; plasminogen, } \\
\text { MMP-1,-2, -9 }\end{array}$ \\
\hline MMP-26 & Matrilysin-2 & n.d. & $\begin{array}{l}\text { Gelatin; collagen IV; } \\
\text { fibronectin; fibrinogen; } \\
\text { vitronectin }\end{array}$ & Pro-MMP-9 \\
\hline \multicolumn{5}{|c|}{ MMPs with fibronectin-domain inserts } \\
\hline MMP-2 & Gelatinase A & $\begin{array}{l}\text { MMP-1, }-7,-13 \text {, } \\
-14,-15,-16 \\
-24, \\
-25 \text {, plasmin }\end{array}$ & $\begin{array}{l}\text { Gelatins; collagens IV, V, } \\
\text { VII, X, and XI; } \\
\text { fibronectin; laminin; } \\
\text { elastin; aggrecan }\end{array}$ & $\begin{array}{l}\text { Pro-TGF- } \beta \text {; FGF receptor I; } \\
\text { MCP-3; IGFBP-5; } \\
\text { pro-IL-1b; galectin-3; } \\
\text { plasminogen }\end{array}$ \\
\hline MMP-9 & Gelatinase B & $\begin{array}{l}\text { MMP-2, }-3,-10 \\
-13 \text {, plasmin }\end{array}$ & $\begin{array}{l}\text { Gelatins; collagens III, IV, } \\
\text { and V; aggrecan; elastin; } \\
\text { entactin; vitronectin; } \\
N \text {-telopeptide of } \\
\text { collagen I }\end{array}$ & $\begin{array}{l}\text { Pro-TGF- } \beta \text {; IL-2 receptor a; } \\
\text { Kit-L; IGFBP-3; } \\
\text { pro-IL-1b; ICAM-1; } \\
\text { galectin-3; plasminogen }\end{array}$ \\
\hline
\end{tabular}


Table 1. Continued

\begin{tabular}{|c|c|c|c|c|}
\hline Members & Alias & Activators & ECM targets & Other targets \\
\hline \multicolumn{5}{|c|}{ Membrane-bound MMP anchored by GPI or a transmembrane domain (TM) } \\
\hline MMP-14 & MT1-MMP (TM) & Furin & $\begin{array}{l}\text { Collagens I, II, and III; } \\
\text { gelatins; aggrecan; } \\
\text { fibronectin; laminin; } \\
\text { fibrin; }\end{array}$ & $\begin{array}{l}\text { pro-MMP-2; pro-MMP-13; } \\
\text { CD44; MCP-3; tissue } \\
\text { transglutaminase }\end{array}$ \\
\hline MMP-15 & MT2-MMP (TM) & Furin & $\begin{array}{l}\text { Fibronectin; laminin; } \\
\text { tenascin; nidogen; } \\
\text { aggrecan; perlecan }\end{array}$ & $\begin{array}{l}\text { Pro-MMP-2; tissue } \\
\text { transglutaminase }\end{array}$ \\
\hline MMP-16 & MT3-MMP (TM) & Furin & $\begin{array}{l}\text { Collagen III; fibronectin; } \\
\text { gelatin }\end{array}$ & $\begin{array}{l}\text { Pro-MMP-2; tissue } \\
\text { transglutaminase }\end{array}$ \\
\hline MMP-17 & MT4-MMP (GPI) & Furin & Gelatin; fibrinogen & n.d. \\
\hline MMP-24 & MT5-MMP (TM) & Furin & Fibrin, gelatin & Pro-MMP-2 \\
\hline MMP-25 & MT6-MMP (GPI) & Furin & $\begin{array}{l}\text { Gelatin; collagen IV; fibrin; } \\
\text { fibronectin; laminin }\end{array}$ & Pro-MMP-2 \\
\hline \multicolumn{5}{|c|}{ ADAMTSs (19 members) } \\
\hline \multicolumn{5}{|c|}{ Hyalectanases } \\
\hline ADAMTS-1 & $\begin{array}{l}\text { METH1, } \\
\text { KIAA1346 }\end{array}$ & n.d. & Aggrecan, versican & n.d. \\
\hline ADAMTS-4 & $\begin{array}{l}\text { KIAA0688, } \\
\text { aggrecanase-1, } \\
\text { ADMP-1 }\end{array}$ & n.d. & $\begin{array}{l}\text { Aggrecan, brevican, } \\
\text { versican, fibronectin, } \\
\text { decorin }\end{array}$ & n.d. \\
\hline ADAMTS-5 & $\begin{array}{l}\text { ADAMTS-11, } \\
\text { aggrecanase-2, } \\
\text { ADMP-2 }\end{array}$ & n.d. & $\begin{array}{l}\text { Aggrecan, versican, } \\
\text { brevican }\end{array}$ & n.d. \\
\hline ADAMTS-8 & METH2 & n.d. & Aggrecan & n.d. \\
\hline ADAMTS-9 & KIAA1312 & n.d. & Aggrecan & n.d. \\
\hline ADAMTS-15 & n.a. & n.d. & Aggrecan & n.d. \\
\hline ADAMTS-20 & n.a. & n.d. & Aggrecan & n.d. \\
\hline \multicolumn{5}{|c|}{ Procollagen N-peptidases } \\
\hline ADAMTS-2 & $\begin{array}{l}\text { Procollagen } N- \\
\text { proteinase }\end{array}$ & n.d. & $\begin{array}{l}\text { Processing of procollagens } \\
\text { I, II, and III } \\
N \text {-propeptides }\end{array}$ & n.d. \\
\hline ADAMTS-3 & KIAA0366 & n.d. & $\begin{array}{l}\text { Processing of procollagen } \\
\text { II } N \text { - propeptides }\end{array}$ & n.d. \\
\hline ADAMTS-14 & n.a. & n.d. & $\begin{array}{l}\text { Processing of procollagen I } \\
N \text {-propeptides }\end{array}$ & n.d. \\
\hline \multicolumn{5}{|l|}{ Others } \\
\hline ADAMTS-13 & vWFCP, C9orf8 & $\begin{array}{l}\text { n.d. } \\
\text { n.d. }\end{array}$ & von Willebrand factor & $\begin{array}{l}\text { n.d. } \\
\text { n.d. }\end{array}$ \\
\hline ADAMTS-7 & n.a. & n.d. & $\begin{array}{l}\text { Cartilage oligomeric } \\
\text { protein }\end{array}$ & n.d. \\
\hline ADAMTS-12 & $\begin{array}{l}\text { PRO4389, } \\
\text { AI605170 }\end{array}$ & n.d. & n.d. & n.d. \\
\hline ADAMTS-6 & n.a. & n.d. & n.d. & n.d. \\
\hline ADAMTS-10 & n.a. & n.d. & n.d. & n.d. \\
\hline ADAMTS-16 & n.a. & n.d. & Aggrecan & n.d. \\
\hline
\end{tabular}


P. Lu et al.

Table 1. Continued

\begin{tabular}{lllll}
\hline Members & \multicolumn{1}{c}{ Alias } & \multicolumn{1}{c}{ Activators } & \multicolumn{1}{c}{ ECM targets } & \multicolumn{1}{c}{ Other targets } \\
\hline ADAMTS-17 & FLJ32769, & n.d. & n.d. & n.d. \\
LOC123271 & & & \\
ADAMTS-18 & ADAMTS-21 & n.d. & Aggrecan & n.d. \\
ADAMTS-19 & n.a. & n.d. & n.d. & n.d. \\
\hline
\end{tabular}

MMP, matrix metalloproteinase; ECM, extracellular matrix; IGFBP, insulin-like growth factor binding protein; n.d., not determined; CTGF, connective tissue growth factor; TGF- $\beta$, transforming growth factor- $\beta$; uPA, urokinase plasminogen activator; HB-EGF, heparin-binding epidermal growth factor; SPARC, secreted protein acidic and rich in cysteine; TGF, transforming growth factor; XMMP, extensible messaging and presence protocol; pro-TNFa, tumor necrosis factor; RANKL, receptor activator of NF-кB ligand; FGF, fibroblast growth factor; ICAM, intercellular adhesion molecule; TM, transmembrane; GPI, glycosylphosphatidylinositol; n.a., not applicable.

Data in table was primarily adapted from references Ghajar et al. (2008), Page-McCaw et al. (2007), Raffetto and Khalil (2008), and Shiomi et al. (2010). Much of the knowledge regarding MMP and ADAMTS proteolytic activities is based in vitro assays and is yet to be confirmed in vivo.

enzymes that remove 6-O-sulfates from heparan sulfate proteoglycans altering Wnt, vascular endothelial growth factor (VEGF), plateletderived growth factor (PDGF), fibroblast growth factor (FGF), and other signaling events (Rosen and Lemjabbar-Alaoui 2010). Hyaluronidases are abundant in the limb bud mesoderm and are responsible for the dynamic expression of their substrate, hyaluronic acid, during early vertebrate limb development (Bastow et al. 2008). Likewise, heparanases are highly expressed in several developmental processes to regulate the levels of heparan sulfate and its associated signaling pathways (Ruiz-Espejo et al. 2003; Ilan et al. 2006).

\section{ECM Modifying Enzymes Are Essential for Regulation of ECM Topography}

Another effective strategy to remodel the ECM is to modulate the levels and organization of ECM components assembled within the protein network. Interstitial collagens, for example, are subject to a myriad of posttranslational modifications, including covalent and noncovalent cross-linking. Both lysyl oxidase (LOX) and lysyl hydroxylases determine the extent of intermolecular cross-linking between collagens and elastin. Up-regulation of collagen cross-linking, for example, because of excess LOX activities, increases tissue tensile strength and matrix stiffness and can profoundly change various cellular behaviors (Levental et al. 2009; Frantz et al. 2010).

ECM Degradation and Remodeling Enzymes Are Regulated at Multiple Levels

As evident from amphibian metamorphosis, ECM degrading and remodeling enzymes are potent and, left unchecked, can have devastating destructive consequences on tissues and cause demise of the whole organism (PageMcCaw et al. 2007; Aitken and Bagli 2009). It thus comes as no surprise that enzyme activities are controlled at multiple levels from transcriptional to posttranslational regulation. At the transcriptional level, expression of ECM remodeling enzymes is tightly controlled so that they are produced in specific cells at specific times (Fig. 1A). Drosophila MMP-2, for example, is specifically expressed in early fly embryos to facilitate tracheal branching morphogenesis (Wang et al. 2009b). Likewise, MMP-2 and -3 activities are required for collective epithelial migration of the mammary gland in postpubertal female mice (Wiseman et al. 2003).

ECM remodeling enzymes are also modulated via posttranscriptional regulation. One way this is accomplished is by distributing proteinases to specific sub/extracellular locations. MMPs and other proteinases, for instance, have been shown to localize specifically in the invadopodia, a special cellular extension 

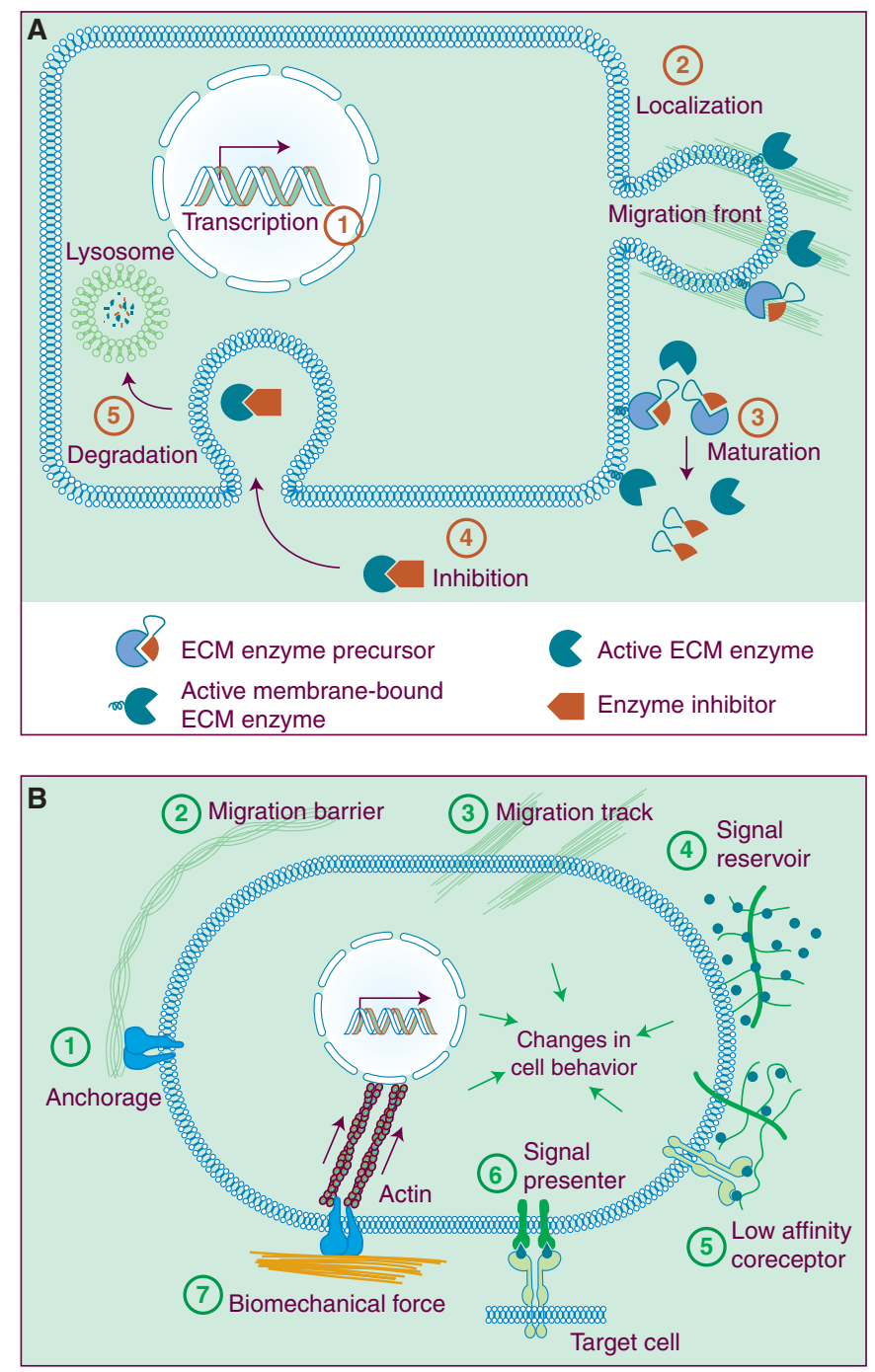

Figure 1. Regulation of ECM remodeling enzymes and biological consequences of ECM dynamics. (A) Some of the mechanisms whereby activities of ECM remodeling enzymes are regulated. The spatiotemporal expression of ECM remodeling enzymes is regulated by transcription factors (1). Once expressed, enzymes may be delivered to specific subcellular locations, including the migration front of a cell. Depending on whether they carry a transmembrane domain, enzymes may anchor in the plasma membrane or be secreted (2). When initially produced, most ECM remodeling enzymes exist as precursors that are inactive until processed and the autoinhibitory prodomain is removed by other proteases (3). Active enzymes can be quickly neutralized by endogenous specific or paninhibitors (4), which then are subject to permanent removal via degradation in the lysosomes (5). (B) The versatile functions of the ECM depend on its diverse physical, biochemical, and biomechanical properties. Anchorage to the basement membrane is essential for various biological processes, including asymmetric cell division in stem cell biology and maintenance of tissue polarity (1). Depending on contexts, the ECM may serve as a barrier (2) or facilitator to cell migration (3). In addition, by binding to growth factor signaling molecules and preventing their otherwise free diffusion, the ECM acts as a sink for these signals and helps shape a concentration gradient (4). Certain ECM components, including heparan sulfate and ECM receptors such as CD44, can selectively bind to different growth factors and function as signal "coreceptors" (5) or "presenters" (6) and help determine the direction of cell-cell communication. Finally, ECM biomechanical properties, including stiffness, have profound influences on various cell behaviors, including cell differentiation (7). 
P. Lu et al.

thought to participate in cell migration (van Hinsbergh and Koolwijk 2008). Likewise, cathepsin $\mathrm{K}$, which is expressed by osteoclasts, accumulates on the basal and acidic side of the cells. Such localization allows cathepsin $\mathrm{K}$ to function in an optimal local microenvironment and ensures efficient degradation and resorption of the bone matrix (Zelzer and Olsen 2003).

Many proteinases have evolved effective strategies to keep their destructive powers under control. MMPs and plasmin, for example, exist as precursors that are enzymatically inactive until they are processed into mature proteinases. For MMPs, this is accomplished by including a prodomain at the amino terminus, which when present masks the catalytic Zn-binding motif (Page-McCaw et al. 2007). The prodomain can be removed by other proteinases, which often are other MMPs (Fig. 1A). For instance, MMP-3 and -10 can cleave precursors of MMP-1, -8 , and -13 to activate them. Likewise, the membrane-type MMP family (MMP-14, $-16,-24$, and -25$)$ can activate pro-MMP-2, and MMP-14 can activate pro-MMP-13 (PageMcCaw et al. 2007; Kessenbrock et al. 2010).

The precursor form of plasmin is plasminogen, which can be processed and activated by plasma kallikrein, urokinase plasminogen activator (uPA), and tissue PA (tPA) (Green and Lund 2005). uPA is generally thought to be the PA involved in tissue remodeling events and functions together with a cofactor uPA receptor ( $\mathrm{UPAR}$ ). In contrast, tPA is primarily expressed by endothelial cells and concerned with blood clotting in the circulatory system (Smith and Marshall 2010). Interestingly, active plasmin can in turn cleave and activate uPA precursor, and thus further facilitate its own activation. By forming such a positive-feedback loop, plasmin activities can be amplified very quickly and have an immediate impact on tissue remodeling (Van den Steen et al. 2001; Smith and Marshall 2010).

Once activated, proteinases can be inactivated by permanent removal through protein degradation. Alternatively, for example, when a temporary or prompt response is desired, their activities can be blocked by endogenous inhibitors. Some of these inhibitors, including $\alpha 2$-macroglobulin, $\alpha 1$-proteinase inhibitor, and $\alpha 1$-chymotrypsin, which are produced in the liver and released into the plasma, are general, and can inhibit a large variety of proteinases (Nagase and Woessner 1999). Tissue inhibitors of metalloproteinases (TIMPs) are potent MMP inhibitors (Fig. 1A). The four members of the vertebrate TIMP family all show two structurally and functionally distinct domains: an amino-terminal domain of about 125 amino acid residues, where much of the MMP inhibitor activity resides, and a carboxy-terminal domain of around 65 residues, which promotes binding between TIMPs and MMPs (Olson et al. 1997; Brew and Nagase 2010). TIMPs bind to MMPs at a 1:1 ratio and the resultant complexes can be recognized by a scavenger receptor and engulfed by macrophages. Although most TIMPs can inhibit various MMPs, some show preference for certain targets. TIMP-1 is less effective than other TIMPs in inhibiting the membrane-type MMPs, MMP14, -16, -19, and -24 (Brew and Nagase 2010). In addition to blocking MMP activities, TIMPs can also inhibit the proteinases of the ADAM and ADAMTS families (Murphy 2008). Similarly, the plasminogen activation system can also be negatively regulated. Thus, whereas plasminogen activator inhibitor (PAI)-1 and -2 inhibit uPA, $\alpha 2$-antiplasmin blocks plasmin activities (Fig. 1A) (Green and Lund 2005).

\section{ECM PROPERTIES DETERMINE EFFECTS ON CELL BEHAVIORS}

The ECM is highly dynamic during organ development and tissue homeostasis. The abnormal changes in the ECM under various disease conditions, including tissue fibrosis and cancer, however, are by no means coincidental; rather, they reflect the important roles that the ECM plays in controlling cell behaviors, deregulation of which can promote, or sometimes initiate disease progression (Egeblad et al. 2010a). Clearly, the essential roles of the ECM are based on its unique physical, biochemical, and biomechanical properties as a network of dynamic, biologically diverse macromolecules. 
Physical Properties Support the Structural Role of the ECM

The physical properties of the ECM often refer to its rigidity, porosity, insolubility, topography, and other characteristics that are essential for its scaffolding role in supporting tissue structure and integrity, and for its role in migration and anchorage of the cell (Fig. 1B) (Daley et al. 2008). ECM plays dynamic and opposing roles in regulating cell migration. On the one hand, basement membrane, as a densely knit fibrillar protein network, is an obvious barrier to migrating cells (Egeblad et al. 2010b; Rozario and DeSimone 2010), such as cranial neural crest (Kang and Svoboda 2005), sea urchin primary mesenchyme cells (Shook and Keller 2003), or cancer cell dissemination (see Fig. 5C) (Thiery et al. 2009). In many cases basement membrane breakdown is neither complete nor permanent. Migration of single cells, including endothelial and immune cells, depends on expression of MMPs at the leading edge and focal degradation of the ECM such that local paths are generated into which cells can freely migrate (van Hinsbergh and Koolwijk 2008; Friedl and Gilmour 2009). Similarly, MMPs are expressed at branching tips of the epithelial network, mediating dynamic ECM remodeling and facilitating collective epithelial migration during branching morphogenesis of the mammary gland (Fig. 2) (Wiseman et al. 2003; Friedl and Gilmour 2009).

On the other hand, ECM cleavage and remodeling can promote cell movement through the formation of oriented or "superhighways," on which cells can migrate (Condeelis and Segall 2003; Wyckoff et al. 2007). In addition, the orientation of ECM components, such as collagen fibers, can profoundly influence the directed migration of cells, possibly by potentiating growth factor receptor signaling or by mechanically reinforcing cell migration (Hynes 2009; Egeblad et al. 2010b). This suggests ECM-dependent cell movement is nonrandom and that cells have machinery in place to sense ECM organization and tension during migration. Remarkably, polystyrene latex beads can also move along collagen fibers in vitro
(Newman et al. 1985) and, when placed in vivo, follow the normal route of neural crest cell migration to a certain extent (BronnerFraser 1982). These data suggest that, in addition to forming migration tracks, the ECM may also provide force, presumably released from collagen assembly or cell-ECM interactions, to propel cell movement.

Finally, through ECM receptors such as integrins, discoidin domain receptors (DDRs), syndecans, and CD44, cells can be immobilized and anchored to the matrix and reciprocally help organize the ECM. Such an anchorage is essential for epithelial cells, including adult stem cells, to maintain tissue polarity, organization, and function (Li and Xie 2005). When ECM anchorage is obliterated, for example, because of loss of integrin function, stem cells fail to maintain a delicate balance between self-renewal and differentiation, and as a consequence, organ homeostasis is disrupted in both invertebrate and vertebrate systems (Tanentzapf et al. 2007; Taddei et al. 2008).

Biochemical Properties Confer the Dynamic and Versatile Signaling Properties of the ECM

As a highly charged protein network rich in polysaccharide modifications, the ECM can bind to a myriad of growth factors and, in so doing, limit the diffusive range and accessibility of ligands to their cognate receptors. Binding to ligands allows the ECM to function as a ligand "reservoir" or "sink" and help create a concentration gradient, an important process especially for potent growth factors, or "morphogens," that can determine cell fate based on their dosage. Indeed, the ECM is essential for shaping the concentration gradient for many growth factors, including bone morphogenetic proteins (BMPs), FGFs, HHs (Hedgehogs), and Wnts (Fig. 1B) (Hynes 2009; Rozario and DeSimone 2010). Moreover, the ECM can participate in ligand maturation. TGF- $\beta$, when first secreted, is in an inactive form and stored in the ECM. It remains as a latent signal until activation via MMP-dependent proteolysis or by mechanical tension (ten Dijke and Arthur 2007). In addition, ECM 
P. Lu et al.
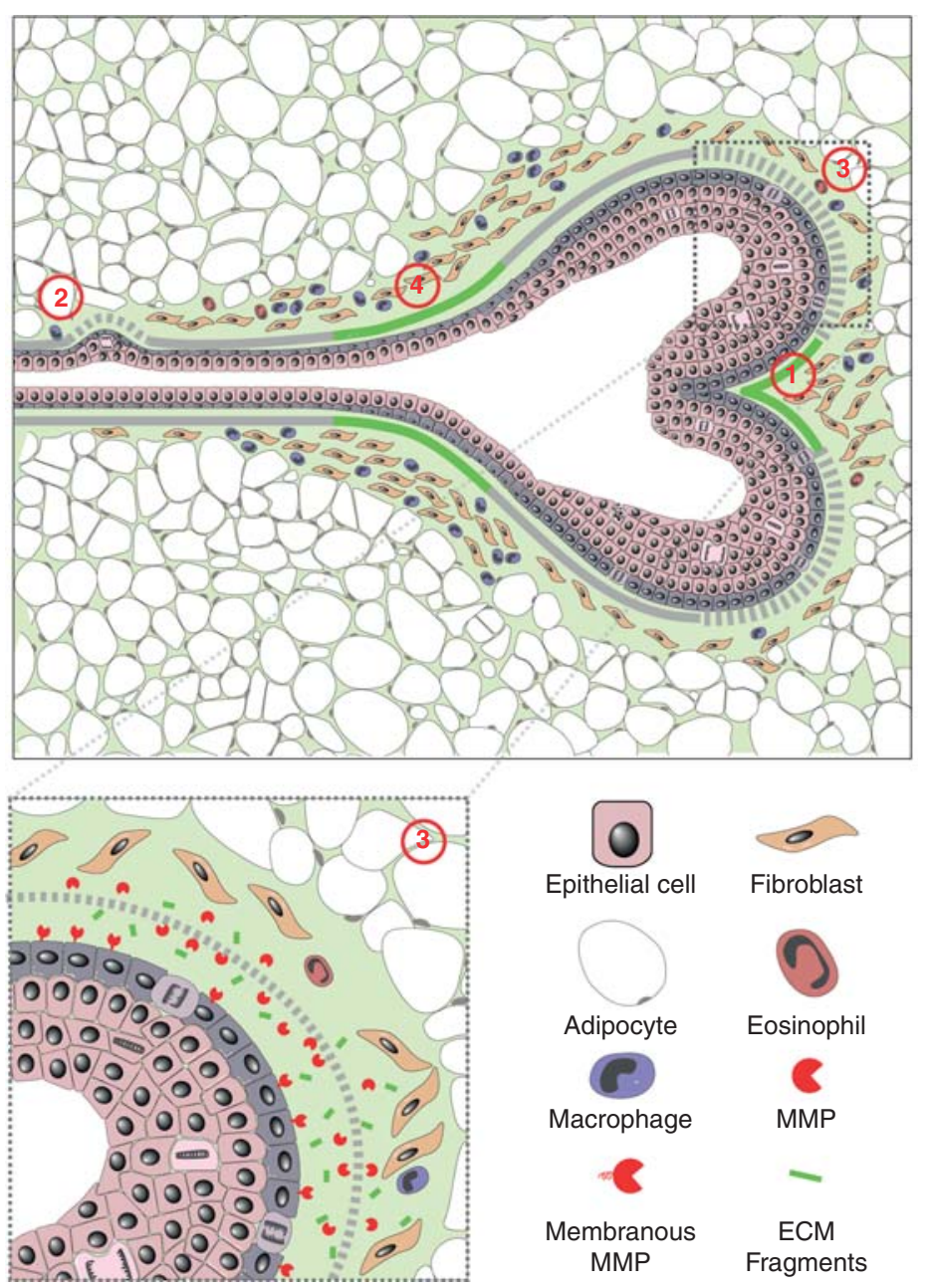

Figure 2. ECM dynamics determine epithelial branch patterning in vertebrate organs. The ECM is dynamic and plays essential roles in various steps during vertebrate epithelial branching morphogenesis. Deposition of newly synthesized ECM (green solid line) including fibronectin and laminin is required for splitting the epithelial bud and primary branching (1). In contrast, partial degradation of the ECM (gray dotted line) by MMP is necessary for epithelial cells to sprout from the side of the duct and undergo side branching (2). MMP activities are also required at the invasion front to maintain a constant ECM remodeling process that is essential for collective epithelial migration (3). MMP activities also generate functional ECM fragments to promote cell proliferation in the tip epithelial cells and thus are essential for supplying the necessary building blocks to sustain the rapid progress of epithelial branching. Interestingly, newly synthesized ECM is also deposited around the "neck" of the branching tip (4). ECM deposition at this place may be important for the ductal remodeling process that has been observed in kidney epithelial branching. (Figure was revised from the original version created by Mark Sternlicht [Sternlicht et al. 2006] and reprinted, with permission, from Elsevier (C) 2006.)

components can enhance the binding affinity between receptors and their growth factor ligands. Heparan sulfate proteoglycan, for example, binds to various growth factors and facilitates interactions between ligands and their receptors (Lonai 2003). Likewise, betaglycan (TGF- $\beta$ type III receptor), an integral membrane proteoglycan, binds to TGF- $\beta$ and presents it to the core type II receptor (Shi and Massagué 2003). 
Importantly, the ECM can selectively bind to growth factors and, as a consequence, help determine the binding specificity between ligands and receptors and the signaling direction of epithelial-mesenchymal crosstalk during development. For example, during vertebrate limb development, heparan sulfate selectively binds FGF10 derived from the mesenchyme but not FGF8 derived from the ectoderm to facilitate FGF signaling targeting the ectodermal cells (Norton et al. 2005). Conversely, CD44, a hyaluronan receptor, selectively binds ectodermal FGF10 to facilitate FGF signaling targeting the mesenchymal cells (Sherman et al. 1998).

The ECM can also participate in signal transduction by directly initiating signaling events, particularly by functioning as precursor of biologically active signaling fragments (Rhodes and Simons 2007). The NC1 fragment, for example, is a proteolytic product of the carboxyl terminus of collagen IV required for promoting cell proliferation in epithelial branching morphogenesis of the submandibular gland (Rebustini et al. 2009). Moreover, the proteoglycan versican is targeted by ADAMTS to generate functional fragments that induce cell death and promote regression of interdigital webbing during mouse limb development (McCulloch et al. 2009). Indeed, a large group of functional fragments, including endostatin, tumstatin, canstatin, arresten and hexastatin, are derived from precursor collagens type IV and XVIII and have potent stimulatory or inhibitory effects on angiogenesis (Mott and Werb 2004). The ECM may directly set off a signaling event by using its endogenous growth-factor-like domains that are present in laminin, tenascin and thrombospondin. It remains a tantalizing possibility, therefore, that these domains could be released by MMP-mediated proteolysis to unleash their signaling potentials much the same way as the above functional fragments (Fig. 1B). The ECM receptors, such as integrins and DDRs, are in essence signal transduction receptors. Binding of the ECM motifs activates the receptors and initiates a cascade of signaling events including Rho and Rock signaling, and directly or indirectly MAPK activities (Hynes
2009). Finally, the ECM can directly participate dynamically in signal transduction by utilizing its biomechanical properties.

Cells Probe the Biomechanical Properties of the ECM via Force

A key area that has recently witnessed major advances is the understanding of how the biomechanical properties of the ECM influence cell behaviors during normal development and disease (Frantz et al. 2010). Strictly speaking, the biomechanical properties of the ECM belong to a subcategory of its physical properties that determine how the ECM reacts to various forms of force, including tensile, compressive, shear, and other types of force loads applied by cells residing in the matrix (Yu et al. 2010). Depending on its composition and topography under different developmental and physiological conditions, the ECM varies greatly in its biomechanical properties, including elasticity, which can range from soft, compliant, to stiff and rigid (Reilly and Engler 2010), and this in turn plays an important role in determining cell behaviors and tissue function.

The notion that ECM elasticity may play an important role in organ homeostasis and function was first suggested by clinical studies. Clinicians have long recognized that diseased tissues have markedly different elasticity than healthy ones (Wolfe 1976; Lieber 2006). Fibrotic tissues, for example, are often unusually stiff and rich in ECM components. Moreover, the extent of tissue stiffness is often a good prognostic indicator for diseases (Frantz et al. 2010). Indeed, increased stiffness of the arterial wall has been shown as a sensitive early marker of atherosclerosis (Claridge et al. 2009). Remarkably, as one of the most dramatic examples, implantation of metal into normal tissue can cause tissue fibrosis and, in some cases, tumor development (Bischoff and Bryson 1964; Hahn et al. 2002), suggesting that changes in tissue stiffness play causative roles in pathology.

The role of ECM elasticity has been confirmed in normal development as well. Different tissues have varying elasticity, from being 
P. Lu et al.

soft in adipose tissue or the brain, somewhat compliant in muscles, to being very stiff and rigid in bones. In addition, ECM elasticity can play an important role in cell differentiation processes (Lopez et al. 2008; Reilly and Engler 2010). Together, differences in ECM biomechanical properties can have great impact on basic cell behaviors and developmental processes.

Cells sense ECM elasticity by exerting forces against the ECM and receiving forces from it. Importantly, not only motile cells, such as immune cells, apply forces against other cells and the matrix to propel their movement. Nonmotile cells, for example, those in adult epithelia, also constantly engage in tugging and pulling of the matrix (Paszek et al. 2005; Lopez et al. 2008; Gehler et al. 2009). How do cells respond to forces? It turns out that cells have developed sophisticated molecular devices to sense mechanical forces during evolution. Most cell types have mechanosensors at the cell surface and inside the cell (Paszek et al. 2005; Berrier and Yamada 2007; Levental et al. 2009; Geiger and Yamada 2011 Schwartz 2011). The nucleus can be regarded as a mechanosensor, whose envelope, filaments, and chromatin are directly connected to the ECM via integrin complexes and cytoskeleton. Indeed, artificially applied forces can change nuclear architecture, chromatin organization, and subsequently, gene expression much faster than conventional signaling transduction cascades triggered by growth factor ligands (Fig. 1B) (Butcher et al. 2009; Wang et al. 2009a). By probing the ECM via forces, therefore, cells can determine and quickly respond to subtle or transient changes in the biomechanical properties of the ECM.

Reciprocal Interactions between Cells and the ECM Allow Cells to Adapt Promptly to Environmental Changes

An important characteristic of the ECM is that its different properties are not independent; rather they are intertwined so that changes in one ECM feature often accompany changes in another category. For instance, when the
ECM stiffens, as, for example, under pathological conditions, its biomechanical properties change and cells respond by exerting markedly different kinds of force (Yu et al. 2010). In addition, stiffer matrix also changes ECM physical properties and, as a consequence, directly impacts how migrating cells interact with the ECM. Thus, linearized, cross-linked collagen bundles, which are quite stiff, potentiate cell migration, whereas a dense network of stiff, cross-linked matrix fibers impedes migration unless MMPs are simultaneously activated (Egeblad et al. 2010b).

Finally, one of the most prominent features of cell-ECM interactions is that they are reciprocal. On the one hand, as the producers and modifiers of the ECM, cells are constantly creating, breaking down, or otherwise rearranging and realigning ECM components to change ECM composition and topography. On the other hand, because of the fundamentally important roles that ECM plays in regulating diverse cell behaviors, any changes in ECM dynamics owing to cellular activities will in turn influence adjacent cells and change their behaviors. By putting into place such a feedback regulatory mechanism between cells and ECM dynamics, cells and tissues become very adaptive to their environment, being able to respond swiftly to subtle environmental changes and adjust their behaviors accordingly.

\section{ECM DYNAMICS IN DEVELOPMENT AND DISEASE}

Consistent with the numerous cell biological functions in which the ECM participates, ECM remodeling is tightly regulated, especially in developmental processes wherein cell behaviors and signaling events are transient and dynamic, for example, during epithelial branching morphogenesis, skeletal development, stem cell maintenance, and differentiation (Rozario and DeSimone 2010). Despite multiple regulatory mechanisms, ECM dynamics can go awry when activities of ECM remodeling proteins are deregulated, resulting in devastating consequences manifested in various human diseases (Muschler and Streuli 2010). 
ECM Dynamics Determine Epithelial Branch Patterning during Vertebrate Organogenesis

Branching morphogenesis is the process whereby a cell or a group of cells expand their surface area by forming cellular or tissue extensions during development. Many vertebrate organs, including the lung, kidney, and mammary gland, undergo branching morphogenesis as an essential part of their ontogeny ( $\mathrm{Lu}$ et al. 2006; Affolter and Caussinus 2008; Andrew and Ewald 2009). It is well documented that mice carrying gain- or loss-of-function alleles of MMPs or TIMPs show defects in branched organs, suggesting that ECM dynamics are involved in epithelial branching morphogenesis (Fata et al. 2004; Sternlicht et al. 2006; PageMcCaw et al. 2007). During branch bifurcation, for example, fibronectin is specifically expressed at the future site where epithelium invaginates to split the epithelial tip. Loss of fibronectin reduces branch number, suggesting that localized fibronectin deposition participates in epithelial bifurcation (Sakai et al. 2003). Likewise, collagen (Fukuda et al. 1988) and laminin (Rebustini et al. 2007) also play a role in epithelial branching (Fig. 2).

Control mechanisms used for side branching are distinct from those for primary branching. Specifically, cells in the duct are much less motile and proliferate less frequently than do tip cells (Shakya et al. 2005; Ewald et al. 2008; Lu et al. 2008a). To sprout a branch from the side, cells have to break down, most likely partially, mature ECM that is much thicker and very different in its physical, biochemical, and biomechanical properties than the ECM surrounding the tip (Silberstein and Daniel 1982; Fata et al. 2004). ECM breakdown can in part be attributed to activities of MMP-3, whose loss blocks side branching, but not primary branching (Wiseman et al. 2003). Indeed, mice overexpressing MMP-3 show excessive side branching and eventual tumor formation in the mammary gland (Sternlicht et al. 1999).

The decision of where to form a branch is finalized by a process called ductal elongation (Watanabe and Costantini 2004; Davies 2005).
The tip ECM is much thinner than mature basement membrane surrounding the duct, presumably by preferential ECM degradation at the invasive front of the epithelium (Fig. 2). Several membrane-type MMPs are expressed in the branching epithelium of the mammary gland (Szabova et al. 2005). For example, MMP-2 is expressed at the epithelial tip, and mice lacking MMP-2 show defect primary but not side branching (Wiseman et al. 2003). In both submandibular and mammary glands, MMP-15 is expressed at the epithelial tip. Interestingly, MMP-15 is required to digest collagen IV to generate the derivative $\mathrm{NC1}$, which is essential to sustain the high proliferation rate of tip cells (Rebustini et al. 2009). However, MMP activities do not always promote epithelial branching, as the data mentioned thus far would indicate. Indeed, excess MMP activities, for example, because of loss of TIMP3 function, can inhibit branching morphogenesis in the mouse lung (Gill et al. 2006). Together, these data suggest that ECM dynamics play multiple roles, including promotion of collective epithelial migration and cell proliferation, during epithelial branching morphogenesis.

ECM Dynamics Are a Fundamental Aspect of Skeletal Development and Remodeling

The ECM of bone is highly dynamic with different components and remodeling enzymes expressed throughout various stages of bone development, from skeletal patterning, condensation, and differentiation, to adult bone remodeling. In the mouse, limb development starts at around embryonic day 9 as small pockets of cells from the lateral plate mesoderm bulge out and form limb buds at the flanks of the body wall (Martin 1998). Following this, skeletal progenitor cells proliferate to promote limb bud outgrowth until a fully patterned limb emerges at E13.5. ECM expression is very dynamic during early limb development. The hyaluronic acid receptor CD44 is specifically expressed in the apical ectodermal ridge (AER) and extinguished when the AER regresses at E12.5 (Sherman et al. 1998). Similar changes in expression of hyaluronic acid, 
P. Lu et al.

fibronectin, and collagen have also been documented (Hall and Miyake 2000).

An essential function of ECM dynamics is to facilitate FGF signaling during the cross talk between the AER and the limb bud mesenchyme. Notably, at this stage, both the AER and mesenchyme can produce FGF ligands to target cells in the opposing tissue compartments (Ornitz and Marie 2002). Specifically, whereas FGF10 is secreted by limb bud mesenchyme to target cells in the AER (Coumoul et al. 2005), FGF8 and, to a lesser extent, FGF4, 9, and 17 are produced by the AER to target cells in the mesenchyme (Sun et al. 2002). So how does FGF signaling acquire its directionality to ensure that FGF ligands function as paracrine signals on target cells in the opposing compartment, rather than as autocrine signals on target cells that produce them? One mechanism is that ECM dynamics participate to ensure the directionality of FGF signaling. The "low-affinity receptor" heparan sulfate is expressed in the apical ectodermal fold (AEF), the equivalent of the mouse AER, during zebrafish fin development. Loss of heparan sulfate in the AEF abrogates only FGF10 signaling, which targets the AEF, but not AEF-FGF8/4 signaling, which targets the mesenchyme (Norton et al. 2005). These data suggest that heparan sulfate can selectively bind FGF10 so that only ectodermal cells are targeted. Conversely, CD44 expressed in the AER can selectively bind to AER-FGFs and "present" them to the underlying limb bud mesenchyme (Sherman et al. 1998). Thus, selective binding by ECM components and their receptors, including CD44, of growth factor ligands allows a creative and expanded use of an otherwise limited number of signaling pathways, possibly an important strategy for the innovation of diverse tissues and organs during metazoan evolution.

At later stages, the proteoglycan versican is highly expressed in the mouse limb bud at the E13 stage and is essential for providing functional fragments required for regression of the AER and interdigital webbing. In the absence of these functional fragments in mice lacking ADAMTS, interdigital mesenchyme fails to regress and, as a consequence, webbing persists in the mutant mouse limbs (Fig. 3) (McCulloch et al. 2009). Thus, in addition to promoting cell proliferation and influencing angiogenesis as mentioned earlier, ECM functional fragments have a wide range of other cellular activities such as inducing apoptosis.

Once skeletal progenitor cells are patterned, they undergo a series of stereotypic morphological changes and differentiation steps until ossification, to give rise to the adult bone. Bone maturation and ossification can occur via either endochondral or intramembraneous development (Aiken and Khokha 2009). ECM expression is very dynamic, accompanying distinct changes in morphology and differentiation status of progenitor cells during this process. In the early limb bud, for example, the mesenchyme is rich in hyaluronic acid and collagen I (Lonai 2003). At the onset of skeletal condensation, hyaluronic acid decreases because of increased hyaluronidase activities, and fibronectin, syndecan, tenascin, and thrombospondin deposition increases (Hall and Miyake 2000; Bastow et al. 2008). Interestingly, a complete absence of hyaluronic acid is also detrimental, as mice lacking Has2 (hyaluronic acid synthase 2) show defective chondrocyte condensation and maturation, and abnormal joint formation (Matsumoto et al. 2009). Likewise, versican plays a role in chondrocyte differentiation and joint morphogenesis (Choocheep et al. 2010).

After condensation, chondrocyte progenitors go through differentiation stages including "resting," proliferation, "hypertrophy," and maturation stages, with cells at each stage forming a distinctive zone that is linearly arranged from both ends toward the center of the bone (Fig. 3). The resting and proliferating chondrocytes make collagen IIa and aggrecan, whereas hypertrophic chondrocytes produce collagen type X and calcify the ECM (Aiken and Khokha 2009). Importantly, both the production of new ECM and the removal of old ECM are essential for proper bone maturation process and increase of bone strength and resilience. Indeed, disorganized columns of chondrocytes and overproduction of hypertrophic chondrocytes are observed in mice lacking MMP-9, -13, or 

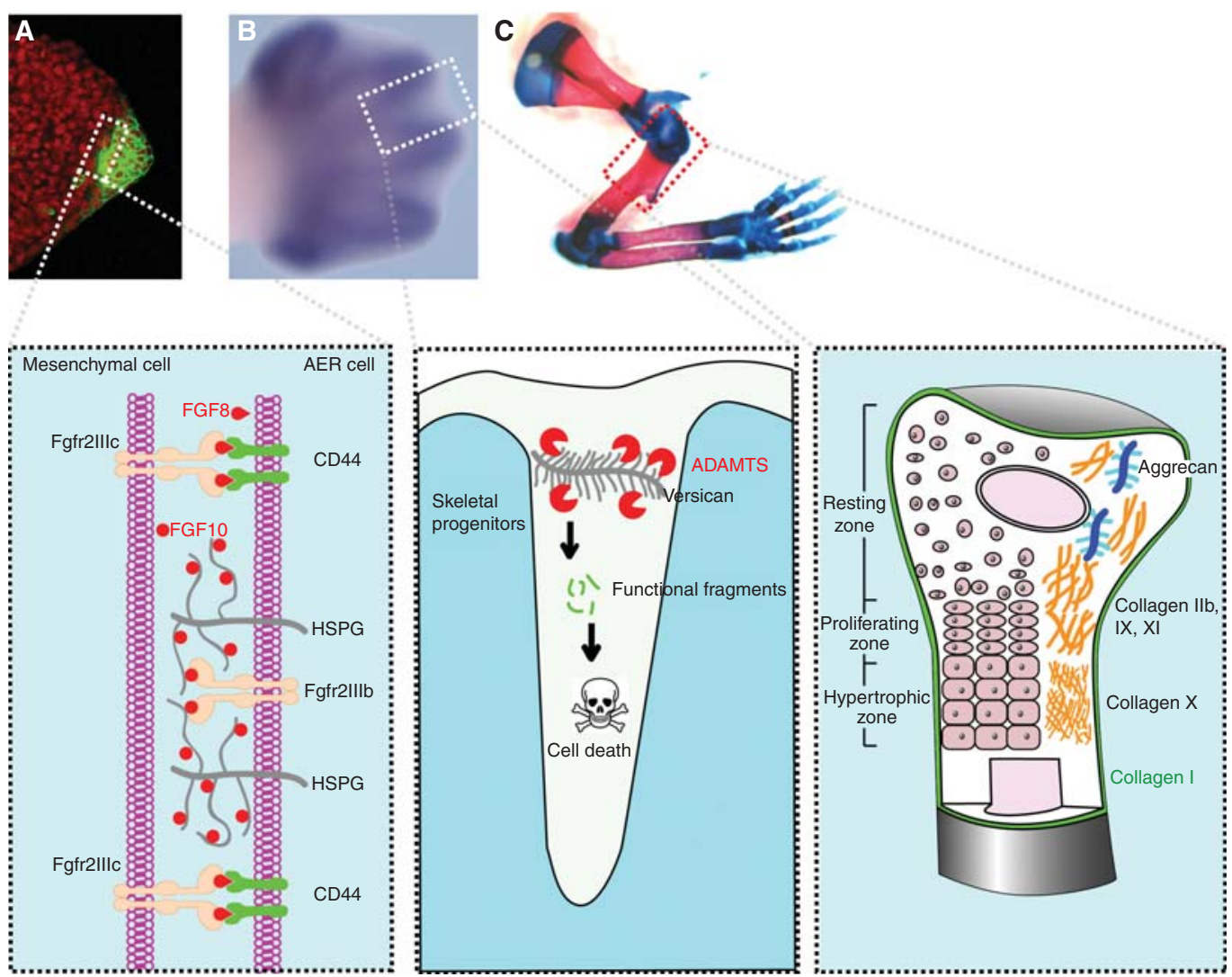

Figure 3. ECM dynamics during digit patterning, regression of interdigital webbing, and bone remodeling. $(A)$ Vibratome section of a mouse limb bud at the 36-somite stage. The epithelial signaling center, the apical ectodermal ridge (AER), was detected by green immunofluorescence against CD44. Section was counterstained with a nuclear dye TO-PRO-3 (red). Inset shows that, through the activities of heparan sulfate and CD44 on the surface of AER cells, AER-FGF8 and mesenchymal FGF10 selectively target cells in the opposing tissue compartments and achieve unidirectional signaling activities during epithelial-mesenchymal cross talk in limb development. (B) In the E13.5 mouse limb bud, skeletal progenitors have been patterned and the interdigital webbing is regressing. Skeletal rudiments, as detected by Sox 9 mRNA in situ hybridization, are evident. Inset shows that versican proteolytic fragments owing to ADAMTS activities are essential for cells in the interdigital mesenchyme to undergo apoptosis and to ensure timely webbing regression. $(C)$ Skeletal preparations of the forelimb of a newborn mouse, with cartilage stained blue and bone stained red. Inset shows that maturing chondrocytes in various "differentiation zones," which express distinctive ECM components. Timely production of corresponding matrix components and removal of "old" matrix are essential for the chondrocyte maturation process. (Images of the limb buds and skeleton were adapted from Lu et al. [2008b] and reprinted, with permission, from The Company of Biologists (C) 2008.)

-14 (Page-McCaw et al. 2007), suggesting that timely removal of the ECM is essential for tissue architecture and chondrocyte progenitor differentiation. Conversely, mice lacking collagen Xa1 showed compressed proliferative and hypertrophic zones and altered mineral deposition (Jacenko et al. 2001). In the mature bone,
ECM is continuously remodeled by activities of the osteoclasts, which degrade the bone matrix, and the osteoblasts, which deposit it. An imbalance between resorption and deposition underlies diseases wherein bone density is altered, including osteopetrosis, and more commonly, osteopenia and osteoporosis. 
P. Lu et al.

Cathepsin $\mathrm{K}$, in particular, is responsible for matrix destruction during bone remodeling (Zelzer and Olsen 2003). Together, ECM dynamics ensure that specific ECM components are deposited at the right times and places to play specific roles, and that ECM is removed in a timely manner once a particular function has been accomplished.

\section{ECM Is an Essential Component of Stem Cell Niches and ECM Dynamics Regulate Stem Cell Differentiation}

Research in stem cell biology has garnered major momentum in the past decade because of its potential applications in biomedical sciences, for instance, in wound healing, regenerative medicine, and cancer biology (Xie and $\mathrm{Li}$ 2007). An important aspect of the stem cell concept is the proposal that there exists a "niche," a special local microenvironment that is essential for the establishment and/or maintenance of stem cell function (Schofield 1978). Recent studies have indicated that an essential component of the niche is ECM macromolecules. Circumstantial evidence for this conclusion was first derived from the widely adopted protocol wherein many ECM receptors are used as markers for the identification and isolation of adult stem cells in various in vitro and in vivo systems (Raymond et al. 2009), which suggests that contact with the ECM is necessary for cells to acquire or maintain stem cell properties.

Indeed, in the subventricular zone of the mouse brain, neural stem cells are not randomly distributed; rather, they localize along the blood vessels. Such localization reflects an anchorage of neural stem cells, which express $\alpha 6 \beta 1$ integrins, on laminin in the vascular basement membrane ECM (Shen et al. 2008). Consistent with these results, loss of function of the ECM receptor integrin, by ablation of genes encoding integrins (Yamashita et al. 2005), or their transcriptional regulator, Myc (Frye et al. 2003), causes reduction of stem cell number. These data suggest that ECM binding is essential for the maintenance and maybe establishment of stem cell properties in the niche. A potential mechanism whereby ECM anchorage regulates stem cell biology is to maintain cell polarity, orient the mitotic spindle, and undergo asymmetric cell division, a fundamental mechanism whereby stem cell self-renewal and differentiation are thought to be determined (Fig. 4) (Yamashita et al. 2005).

ECM components can also directly influence stem cell biology. In the hematopoietic system, osteopontin, a niche component secreted by osteoblasts, negatively regulates the number of stem cells (Kollet et al. 2006; Lymperi et al. 2010). Nephronectin, a basement membrane component produced by bulge cells in the hair follicle, is required for creating a smooth muscle stem cell niche (Fujiwara et al. 2011). Likewise, both tenascin $\mathrm{C}$ and biglycan are critical stem cell niche components of the subventricular zone and tendon systems, respectively (Garcion et al. 2004; Bi et al. 2007). One way ECM may function in stem cell niches is to modulate various growth factor signaling pathways that are essential for stem cell biology. For example, FGF2 and BMP4 signaling, which play an important role in neural stem cell biology, are modulated by the levels of tenascin $\mathrm{C}$ in the subventricular zone (Garcion et al. 2004). Likewise, the accessibility of the ligand Upd, which activates the JAK/STAT signaling pathway and plays an essential role in stem cell biology of the fly testis, is modulated by the ECM as well (Yamashita et al. 2005).

The biomechanical properties of the ECM may also play an important role in regulating stem cell biology. Mesenchymal stem cells (MSCs) grown on polymer gels with similar elasticity to the brain express neuronal markers and morphology, whereas those grown on gels that are semi-compliant like smooth and skeletal muscle tissues or rigid like the bone, express muscle or bone proteins, respectively (Engler et al. 2006). Likewise, muscle stem cells grown on soft hydrogels with elasticity mimicking that of real muscle differentiate into functional muscle (Gilbert et al. 2010), highlighting the great promise that tissue engineering may hold in regenerative medicine. Together, by changing the ECM composition and topography, and thus the niche environment, ECM dynamics may be integrated into the regulatory network 


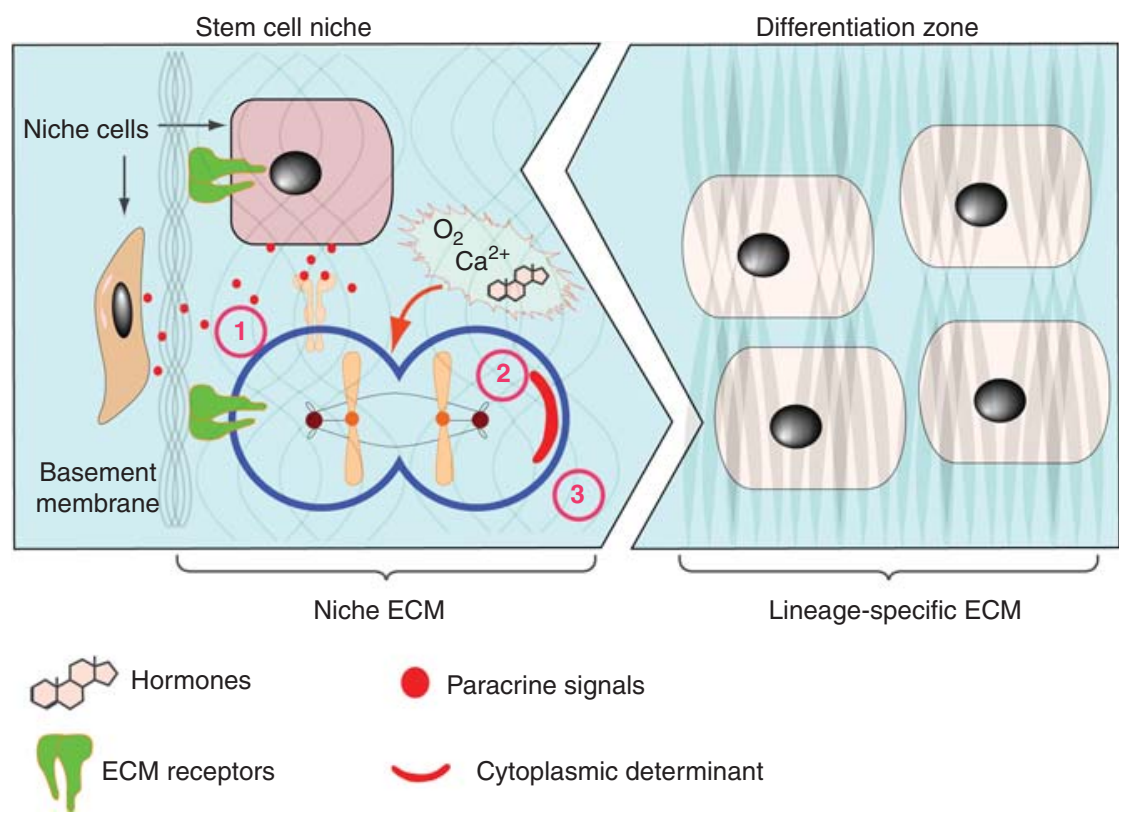

Figure 4. ECM dynamics in maintenance of the stem cell niche and cell differentiation. Together with hormones, oxygen, and $\mathrm{Ca}^{2+}$, the ECM may play multiple roles in maintaining stem cell properties. The ECM anchors stem cells in the niche, and thus allows them to be exposed to paracrine (1) and cell-cell contact signals (not depicted) that are essential for maintaining stem cell properties. Anchorage is also important for orienting the mitotic spindle and makes it possible for stem cells to undergo asymmetric cell division (2), which is essential for stem cell self-renewal and generation of daughter cells that are destined to undergo cell differentiation. The exact mechanism whereby ECM anchorage controls asymmetric cell division remains unclear, although one possibility is to allow cytoplasmic cell-fate determinants to be differentially distributed between the daughter cells. The ECM may also maintain stem cell properties via its many other features including biochemical signaling potentials and, as has become increasingly clear, its biomechanical properties including ECM stiffness, which may play a major role in cell-fate determination (3).

that modulates the stem cell differentiation processes (Lutolf et al. 2009).

\section{ECM Dynamics in Cancer Initiation and Progression}

There is growing interest in understanding the role of abnormal ECM dynamics, especially in the "cancer stem cell niche" and "metastatic niche," at major stages of cancer progression. Recent studies have highlighted the role of the ECM and shown the importance of deregulated ECM dynamics in molecular etiology of cancer development. Excess ECM production or reduced ECM turnover, for example, are a salient feature in tissue fibrosis of many organs (Frantz et al. 2010). Breast density, which in part reflects elevated collagen and proteoglycan levels, is a prognostic indicator of breast cancer treatment and response in young female patients (Wolfe 1976; Lieber 2006). Conversely, softening of the breast after tamoxifen treatment is a good response and prognostic indicator for breast cancer treatment (Lasco et al. 2006; Cuzick et al. 2011). Increased breast density and high collagen content may be because of enhanced deposition, reduced remodeling, or heightened posttranslational modifications such as crosslinking of certain ECM components. For example, various collagens, including collagen I, II, III, V, and IX, show increased deposition during tumor formation (Egeblad et al. 2010b). In addition to changes in its composition, the architecture of tumor-associated ECM is 
P. Lu et al.

fundamentally different from that of the normal tissue stroma; rather than relaxed nonoriented fibrils, the collagen I in breast tumors is often highly linearized and either oriented adjacent to the epithelium or projecting perpendicularly into the tissue (Levental et al. 2009; Egeblad et al. 2010b).

Consistent with the changes in ECM composition and topography, expression of many ECM remodeling enzymes is often deregulated in human cancers. For example, heparanases, sulfatases, and, most notably, many MMPs are frequently overexpressed in various cancers (Ilan et al. 2006; Page-McCaw et al. 2007; Kessenbrock et al. 2010). Excess activities of LOX, which cross-links collagen fibers and other ECM components to increase ECM stiffness, are also frequently observed in various carcinomas (Levental et al. 2009). Major contributors to abnormal ECM metabolism are stromal fibroblasts, particularly "cancer-associated fibroblasts" (CAFs). However, immune cells and epithelial cells in late-stage tumors also contribute (Bhowmick et al. 2004; Egeblad et al. 2010b).

An important question is whether abnormal ECM buildup is merely one of the many secondary outcomes of aberrant cell behaviors, or whether it has any functional consequences during cancer progression. LOX overexpression increases ECM stiffness and promotes tumor cell invasion and progression; conversely, inhibition of LOX reduces tissue fibrosis and tumor incidence in the Neu breast cancer model (Levental et al. 2009). These data suggest that collagen deregulation and ECM stiffness are more than just a secondary outcome, but may play a causative role in cancer pathogenesis. Interestingly, overexpression of LOX alone is insufficient to cause tumors to form (Levental et al. 2009), suggesting that deregulation of ECM dynamics is a "coconspirator," rather than a primary inducer of tumorigenesis in the breast. Together, deregulation of ECM dynamics is common in various human diseases and plays an important role in cancer development.

Deregulated ECM dynamics play an important role in cancer initiation and progression. As a potent facilitator and modifier, the ECM can promote many growth factor signaling pathways such as Wnt, FGF, and $\mathrm{HH}$, all of which have potent oncogenic potentials when excessive. Consistently, many ECM components, such as heparan sulfate proteoglycan (HSPG), are frequently overproduced in cancer (Nasser 2008; Orian-Rousseau 2010). In addition, ECM components with deregulated biomechanical properties can also be oncogenic. Increases in collagen deposition or ECM stiffness, alone or in combination, up-regulate integrin signaling, and thus promote cell survival and proliferation (Egeblad et al. 2010b). Indeed, increased collagen cross-linking and ECM stiffness owing to LOX overproduction facilitate Neu-mediated oncogenic transformation (Levental et al. 2009). Because various ECM components or their functional fragments have pro- or antiapoptotic effects, it is conceivable that deregulation of ECM remodeling can lead to an evasion of apoptosis by mutant cells.

Considering that modulation of ECM biomechanical properties is an effective mechanism to regulate cell differentiation and maintain tissue polarity, both of which are corrupted during cancer progression (Feigin and Muthuswamy 2009), it is reasonable to suggest that deregulated ECM dynamics can derail these two characteristics and contribute to carcinogenesis (Fig. 5). An important role that excess MMPs may play in cancer is to remove the physical barrier posed by basement membrane ECM to promote tissue invasion. Moreover, ECM topographical changes, including thickening and linearization of collagen fibers, are often observed in areas where cancer epithelial cells invade and are adjacent to the tumor vasculature (Egeblad et al. 2010b). Consistently, studies using live imaging have shown that cancer cells migrate rapidly on collagen fibers in areas enriched in collagen (Condeelis and Segall 2003; Egeblad et al. 2010b). Together, deregulation of ECM dynamics promotes cancer cell proliferation, loss of cell differentiation, and cancer cell invasion, and thus plays essential roles in cancer progression.

Importantly, an abnormal ECM influences the behavior of not only cancer cells but those of stromal, endothelial, and immune cells of the local microenvironment as well. Many 
ECM Degradation and Remodeling
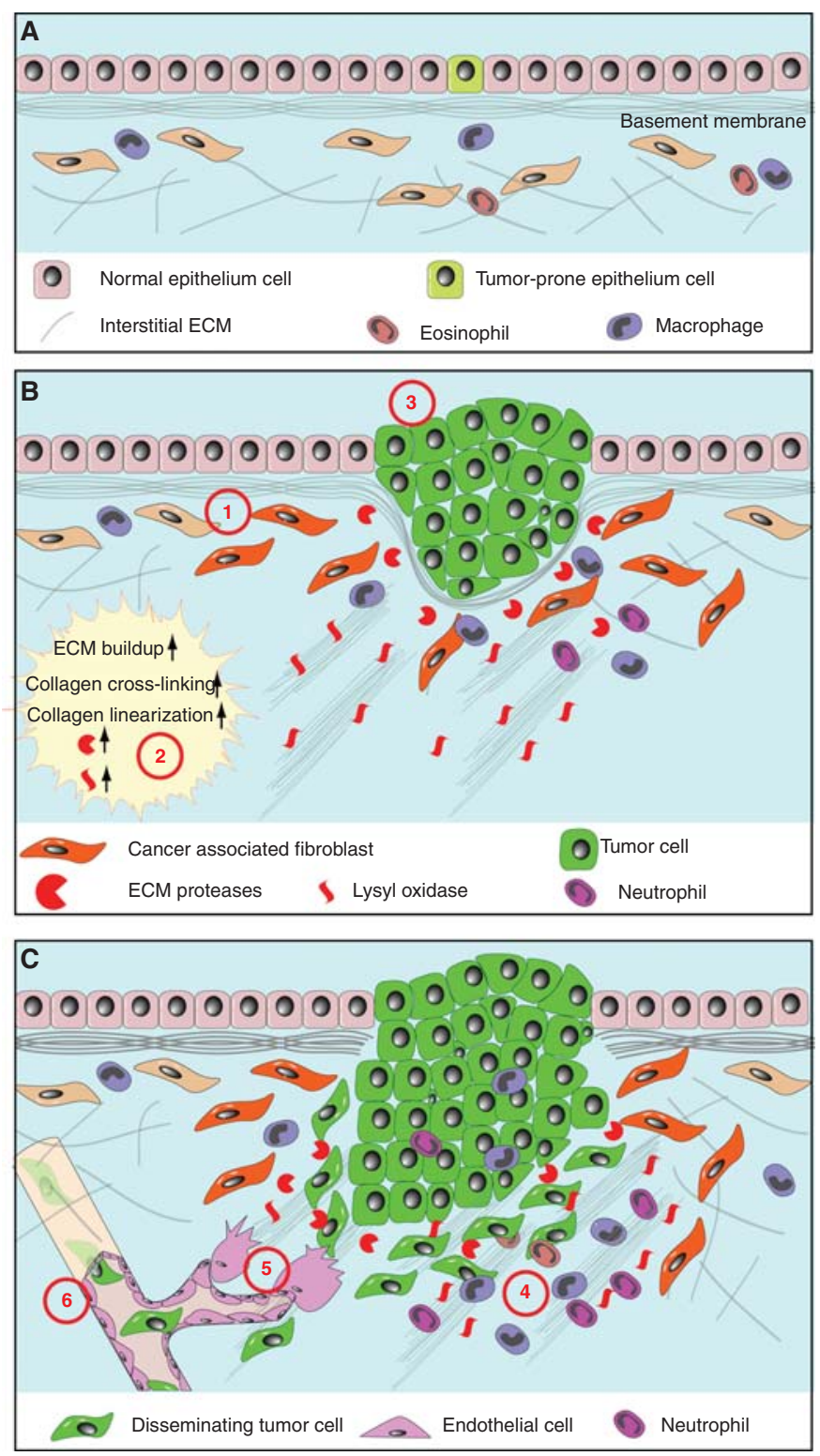

Figure 5. Abnormal ECM dynamics promote cancer initiation and progression. (A) Normal ECM dynamics are essential for maintaining tissue integrity and keep rare tumor-prone cells in check by maintaining an overall healthy microenvironment. With age or under pathological conditions, tissues can enter a series of tumorigenic events $(B)$. One of the earlier events is the generation of "activated" fibroblasts or cancer-associated fibroblasts (1), which contributes to abnormal ECM buildup and deregulated expression of ECM remodeling enzymes (2). Abnormal ECM may have profound impacts on surrounding cells, including epithelial, endothelial, immune cells, and other stromal cell types. Deregulated ECM, for example, may promote epithelial cellular transformation and hyperplasia (3). Many aspects of immune cell biology, including infiltration, maturation, activation, etc., may also be greatly influenced by deregulated ECM dynamics. $(C)$ In late-stage tumors, immune cells are often recruited to tumor sites to promote cancer progression (4). In addition, deregulated ECM affects various aspects of vascular biology and promotes tumor-associated angiogenesis (5). Creation of a leaky tumor vasculature in turn facilitates tumor cell invasion and metastasis to distant sites (6). 
P. Lu et al.

fragments of ECM components are chemotactic and can attract endothelial and inflammatory cells to migrate into areas of active tumor cell proliferation and growth (Fig. 5) (Mott and Werb 2004). As in normal development, new ECM is deposited to form basement membrane to surround blood vessels during tumor angiogenesis. Importantly, however, basement membrane ECM of the tumor vasculature is more porous and leaky than normal and promotes tumor cell metastasis during cancer progression (Egeblad et al. 2010a). Collagen I and its derivative fragments, which are chemoattractants for immune cells, are often up-regulated in cancers and their up-regulation correlates with increased numbers of macrophages and neutrophils at tumor sites. Consistent with these results, activation of collagen receptor DDR1 promotes macrophage infiltration in atherosclerotic plaques (Egeblad et al. 2010b).

The ECM also regulates the activation of immune cells. Although collagen type I promotes infiltration of certain immune cells, it also inhibits the ability of macrophages to kill cancer cells by blocking polarization, and thus activation of macrophages (Egeblad et al. 2010b). The inhibitory effect of collagen I on immune cells is likely mediated by its binding with the leukocyte-associated Ig-like receptor (LAIR), which is expressed on most immune cells (Fig. 5) (Frantz et al. 2010). Finally, research has also shown that increased ECM stiffness promotes integrin-mediated adhesion complex assembly and T-cell activation (Egeblad et al. 2010b; Geiger and Yamada 2011; Schwartz 2011).

Thus, in addition to deregulating epithelial or stem cell behaviors in the local microenvironment, abnormal ECM dynamics also cause aberrant stromal cell behaviors, leading to tumor-promoting angiogenesis and inflammation by endothelial cells and immune cells, respectively.

\section{CONCLUSIONS AND FUTURE PERSPECTIVES}

It is unequivocal that ECM components are not only functionally diverse, being able to trigger a wide range of cellular activities, but also extremely dynamic, constantly undergoing remodeling processes wherein one or more of their essential properties are modified. Together with the reciprocal nature of cell-ECM interactions, it is evident that modulation of ECM dynamics is an effective strategy for cells to respond to environmental changes, adjust their behaviors accordingly, and maintain tissue integrity and function.

An important area of future research is to identify the diverse and novel roles of ECM components, especially with regard to its distinct physical, biochemical, and biomechanical properties, in various cellular and developmental processes. The fact that different ECM components can selectively bind to growth factors, which are often repeatedly used in multiple tissue compartments and at different times of organ development, and mediate directional signaling, has profound implications in understanding normal development and cancer. It is conceivable that deregulation of ECM dynamics may lead to a disruption of directional epithelial-mesenchymal cross talk, the basis of normal organ formation and homeostasis. Understanding the roles of ECM dynamics in the dialogues between different tissue components, therefore, can lead to a better understanding of the etiology of certain human congenital defects and cancers.

Considering the advances that have been made in the field of ECM biomechanics, an important next challenge will be to understand how different tissues establish and maintain their distinctive elasticity, and how normal tissue elasticity may be lost with age or under disease conditions. Abnormal ECM stiffness, as observed in tissue fibrosis, clearly plays an important role in cancer progression. It remains unclear, however, at the molecular level, how such abnormalities lead to changes in cell behavior and how different cell types may be affected.

Although the niche role has been well accepted in stem cell biology and has an increasing role in the cancer stem cell concept, and evidence supporting the ECM as an important and dynamic component of the niche is emerging, the mechanisms whereby ECM components function in stem cell biology still remain 
sketchy. What are the ECM components in the established invertebrate and vertebrate model systems? How do they interact with niche cells and paracrine signals and participate in the establishment and maintenance of stem cells? How does the niche ECM differ from non-niche ECM, and why does the former maintain stem cell properties, whereas the latter promotes differentiation? Clearly, a better understanding of the role of ECM biomechanics and dynamics in adult stem cell biology will have profound implications in the field of tissue engineering and regenerative medicine.

\section{ACKNOWLEDGMENTS}

We apologize to authors whose work we could not cite owing to space constraints. We thank Dr. Anthony Howell and members of the Lu laboratory for critical reading of the manuscript. This work was supported by grants from the Breakthrough Breast Cancer to P.L., the National Institutes of Health (R03 HD060807 to P.L., R01 CA057621 to Z.W., U01 ES019458 to Z.W. and V.M.W., and R01 CA138818 to V.M.W.).

\section{REFERENCES}

Affolter M, Caussinus E. 2008. Tracheal branching morphogenesis in Drosophila: New insights into cell behaviour and organ architecture. Development 135: 2055-2064.

Aiken A, Khokha R. 2009. Unraveling metalloproteinase function in skeletal biology and disease using genetically altered mice. Biochim Biophys Acta 1803: 121-132.

Aitken KJ, Bagli DJ. 2009. The bladder extracellular matrix. Part I: Architecture, development and disease. Nat Rev Urol 6: 596-611

Andrew DJ, Ewald AJ. 2009. Morphogenesis of epithelial tubes: Insights into tube formation, elongation, and elaboration. Dev Biol 341: 34-55.

Apte SS. 2009. A disintegrin-like and metalloprotease (reprolysin-type) with thrombospondin type 1 motif (ADAMTS) superfamily: Functions and mechanisms. J Biol Chem 284: 31493-31497.

Bastow ER, Byers S, Golub SB, Clarkin CE, Pitsillides AA, Fosang AJ. 2008. Hyaluronan synthesis and degradation in cartilage and bone. Cell Mol Life Sci 65: 395-413.

Berardi N, Pizzorusso T, Maffei L. 2004. Extracellular matrix and visual cortical plasticity: Freeing the synapse. Neuron 44: 905-908.

Berrier AL, Yamada KM. 2007. Cell-matrix adhesion. J Cell Physiol 213: 565-573.
Bhowmick NA, Neilson EG, Moses HL. 2004. Stromal fibroblasts in cancer initiation and progression. Nature 432: $332-337$.

Bi Y, Ehirchiou D, Kilts TM, Inkson CA, Embree MC, Sonoyama W, Li L, Leet AI, Seo BM, Zhang L, et al. 2007. Identification of tendon stem/progenitor cells and the role of the extracellular matrix in their niche. Nat Med 13: 1219-1227.

Bischoff F, Bryson G. 1964. Carcinogenesis through solid state surfaces. Prog Exp Tumor Res 5: 85-133.

Brew K, Nagase H. 2010. The tissue inhibitors of metalloproteinases (TIMPs): An ancient family with structural and functional diversity. Biochim Biophys Acta 1803: 55-71.

Bronner-Fraser M. 1982. Distribution of latex beads and retinal pigment epithelial cells along the ventral neural crest pathway. Dev Biol 91: 50-63.

Butcher DT, Alliston T, Weaver VM. 2009. A tense situation: Forcing tumour progression. Nat Rev Cancer 9: 108-122.

Cawston TE, Young DA. 2010. Proteinases involved in matrix turnover during cartilage and bone breakdown. Cell Tissue Res 339: 221-235.

Choocheep K, Hatano S, Takagi H, Watanabe H, Kimata K, Kongtawelert P. 2010. Versican facilitates chondrocyte differentiation and regulates joint morphogenesis. J Biol Chem 285: 21114-21125.

Claridge MW, Bate GR, Hoskins PR, Adam DJ, Bradbury AW, Wilmink AB. 2009. Measurement of arterial stiffness in subjects with vascular disease: Are vessel wall changes more sensitive than increase in intima-media thickness? Atherosclerosis 205: 477-480.

Condeelis J, Segall JE. 2003. Intravital imaging of cell movement in tumours. Nat Rev Cancer 3: 921-930.

Coumoul X, Shukla V, Li C, Wang RH, Deng CX. 2005. Conditional knockdown of Fgfr2 in mice using Cre-LoxP induced RNA interference. Nucleic Acids Res 33: e102. doi: $10.1093 /$ nar/gnil00.

Cuzick J, Warwick J, Pinney E, Duffy SW, Cawthorn S, Howell A, Forbes JF, Warren RM. 2011. Change in breast density as a predictor of breast cancer risk reduction for tamoxifen: Results from IBIS-1. J Natl Cancer Inst doi: 101093/jnci/djr079.

Daley WP, Peters SB, Larsen M. 2008. Extracellular matrix dynamics in development and regenerative medicine. $J$ Cell Sci 121: 255-264.

Davies JA. 2005. Watching tubules glow and branch. Curr Opin Genet Dev 15: 364-370.

Egeblad M, Werb Z. 2002. New functions for the matrix metalloproteinases in cancer progression. Nat Rev Cancer 2: $161-174$.

Egeblad M, Nakasone ES, Werb Z. 2010a. Tumors as organs: Complex tissues that interface with the entire organism. Dev Cell 18: 884-901.

Egeblad M, Rasch MG, Weaver VM. 2010b. Dynamic interplay between the collagen scaffold and tumor evolution. Curr Opin Cell Biol 22: 697-706.

Engler AJ, Sen S, Sweeney HL, Discher DE. 2006. Matrix elasticity directs stem cell lineage specification. Cell 126: $677-689$. 
P. Lu et al.

Engler AJ, Humbert PO, Wehrle-Haller B, Weaver VM. 2009 Multiscale modeling of form and function. Science 324: 208-212.

Ewald AJ, Brenot A, Duong M, Chan BS, Werb Z. 2008. Collective epithelial migration and cell rearrangements drive mammary branching morphogenesis. Dev Cell 14: $570-581$.

Fata JE, Werb Z, Bissell MJ. 2004. Regulation of mammary gland branching morphogenesis by the extracellular matrix and its remodeling enzymes. Breast Cancer Res 6: $1-11$.

Feigin ME, Muthuswamy SK. 2009. Polarity proteins regulate mammalian cell-cell junctions and cancer pathogenesis. Curr Opin Cell Biol 21: 694-700.

Frantz C, Stewart KM, Weaver VM. 2010. The extracellular matrix at a glance. J Cell Sci 123: 4195-4200.

Friedl P, Gilmour D. 2009. Collective cell migration in morphogenesis, regeneration and cancer. Nat Rev Mol Cell Biol 10: 445-457.

Frye M, Gardner C, Li ER, Arnold I, Watt FM. 2003. Evidence that Myc activation depletes the epidermal stem cell compartment by modulating adhesive interactions with the local microenvironment. Development 130: 2793-2808.

Fujiwara H, Ferreira M, Donati G, Marciano DK, Linton JM, Sato Y, Hartner A, Sekiguchi K, Reichardt LF, Watt FM. 2011. The basement membrane of hair follicle stem cells is a muscle cell niche. Cell 144: 577-589.

Fukuda Y, Masuda Y, Kishi J, Hashimoto Y, Hayakawa T, Nogawa H, Nakanishi Y. 1988. The role of interstitial collagens in cleft formation of mouse embryonic submandibular gland during initial branching. Development 103: $259-267$.

Fukumoto S, Yamada Y. 2005. Review: Extracellular matrix regulates tooth morphogenesis. Connect Tissue Res 464: 220-226.

Garcion E, Halilagic A, Faissner A, ffrench-Constant C. 2004. Generation of an environmental niche for neural stem cell development by the extracellular matrix molecule tenascin C. Development 131: 3423-3432.

Gehler S, Baldassarre M, Lad Y, Leight JL, Wozniak MA, Riching KM, Eliceiri KW, Weaver VM, Calderwood DA, Keely PJ. 2009. Filamin A-beta1 integrin complex tunes epithelial cell response to matrix tension. Mol Biol Cell 20: 3224-3238.

Geiger B, Yamada KM. 2011. Molecular architecture and function of matrix adhesions. Cold Spring Harb Perspect Biol 3: a005033.

Ghajar CM, George SC, Putnam AJ. 2008. Matrix metalloproteinase control of capillary morphogenesis. Crit Rev Eukaryot Gene Expr 18: 251-278.

Gilbert PM, Havenstrite KL, Magnusson KEG, Sacco A, Leonardi NA, Kraft P, Nguyen NK, Thrun S, Lutolf MP, Blau HM. 2010. Substrate elasticity regulates skeletal muscle stem cell self-renewal in culture. Science 329: 1078-1081.

Gill SE, Pape MC, Leco KJ. 2006. Tissue inhibitor of metalloproteinases 3 regulates extracellular matrix-cell signaling during bronchiole branching morphogenesis. Developmental Biology 298: 540-554.
Green KA, Lund LR. 2005. ECM degrading proteases and tissue remodelling in the mammary gland. Bioessays 27: 894-903.

Hahn FF, Guilmette RA, Hoover MD. 2002. Implanted depleted uranium fragments cause soft tissue sarcomas in the muscles of rats. Environ Health Perspect 110: 51-59.

Hall BK, Miyake T. 2000. All for one and one for all: Condensations and the initiation of skeletal development. Bioessays 22: $138-147$.

Har-el R, Tanzer ML. 1993. Extracellular matrix. 3: Evolution of the extracellular matrix in invertebrates. FASEB J 7: 1115-1123.

Hutter H, Vogel BE, Plenefisch JD, Norris CR, Proenca RB, Spieth J, Guo C, Mastwal S, Zhu X, Scheel J, et al. 2000. Conservation and novelty in the evolution of cell adhesion and extracellular matrix genes. Science 287: 989-994.

Huxley-Jones J, Pinney JW, Archer J, Robertson DL, BootHandford RP. 2009. Back to basics-How the evolution of the extracellular matrix underpinned vertebrate evolution. Int J Exp Pathol 90: 95-100.

Hynes RO. 2009. The extracellular matrix: Not just pretty fibrils. Science 326: 1216-1219.

Ilan N, Elkin M, Vlodavsky I. 2006. Regulation, function and clinical significance of heparanase in cancer metastasis and angiogenesis. Int J Biochem Cell Biol 38: 2018-2039.

Jacenko O, Chan D, Franklin A, Ito S, Underhill CB, Bateman JF, Campbell MR. 2001. A dominant interference collagen X mutation disrupts hypertrophic chondrocyte pericellular matrix and glycosaminoglycan and proteoglycan distribution in transgenic mice. Am J Pathol 159: 2257-2269.

Kang P, Svoboda KKH. 2005. Epithelial-mesenchymal transformation during craniofacial development. J Dent Res 84: 678-690.

Kessenbrock K, Plaks V, Werb Z. 2010. Matrix metalloproteinases: Regulators of the tumor microenvironment. Cell 141: 52-67.

Kollet O, Dar A, Shivtiel S, Kalinkovich A, Lapid K, Sztainberg Y, Tesio M, Samstein RM, Goichberg P, Spiegel A, et al. 2006. Osteoclasts degrade endosteal components and promote mobilization of hematopoietic progenitor cells. Nat Med 12: 657-664.

Lasco A, Gaudio A, Morini E, Morabito N, Nicita-Mauro C Catalano A, Denuzzo G, Sansotta C, Xourafa A, Macri I, et al. 2006. Effect of long-term treatment with raloxifene on mammary density in postmenopausal women. Menopause 13: 787-792.

Levental KR, Yu H, Kass L, Lakins JN, Egeblad M, Erler JT, Fong SF, Csiszar K, Giaccia A, Weninger W, et al. 2009. Matrix crosslinking forces tumor progression by enhancing integrin signaling. Cell 139: 891-906.

Li L, Xie T. 2005. Stem cell niche: Structure and function. Annu Rev Cell Dev Biol 21: 605-631.

Lieber MM. 2006. Towards an understanding of the role of forces in carcinogenesis: A perspective with therapeutic implications. Riv Biol 99: 131-160.

Lonai P. 2003. Epithelial mesenchymal interactions, the ECM and limb development. J Anat 202: 43-50. 
Lopez JI, Mouw JK, Weaver VM. 2008. Biomechanical regulation of cell orientation and fate. Oncogene 27: 6981-6993.

Lu P, Sternlicht MD, Werb Z. 2006. Comparative mechanisms of branching morphogenesis in diverse systems. J Mammary Gland Biol Neoplasia 11: 213-228.

Lu P, Ewald AJ, Martin GR, Werb Z. 2008a. Genetic mosaic analysis reveals FGF receptor 2 function in terminal end buds during mammary gland branching morphogenesis. Dev Biol 321: 77-87.

Lu P, Yu Y, Perdue Y, Werb Z. 2008b. The apical ectodermal ridge is a timer for generating distal limb progenitors. Development 135: 1395-1405.

Lutolf MP, Gilbert PM, Blau HM. 2009. Designing materials to direct stem-cell fate. Nature 462: 433-441.

Lymperi S, Ferraro F, Scadden DT. 2010. The HSC niche concept has turned 31. Has our knowledge matured? Ann NY Acad Sci 1192: 12-18.

Martin GR. 1998. The roles of FGFs in the early development of vertebrate limbs. Genes Dev 12: 1571-1586.

Matsumoto K, Li Y, Jakuba C, Sugiyama Y, Sayo T, Okuno M, Dealy CN, Toole BP, Takeda J, Yamaguchi Y, et al. 2009. Conditional inactivation of Has2 reveals a crucial role for hyaluronan in skeletal growth, patterning, chondrocyte maturation and joint formation in the developing limb. Development 136: 2825-2835.

McCulloch DR, Nelson CM, Dixon LJ, Silver DL, Wylie JD, Lindner V, Sasaki T, Cooley MA, Argraves WS, Apte SS 2009. ADAMTS metalloproteases generate active versican fragments that regulate interdigital web regression. Dev Cell 17: 687-698.

Mott JD, Werb Z. 2004. Regulation of matrix biology by matrix metalloproteinases. Curr Opin Cell Biol 16: $558-564$.

Murphy G. 2008. The ADAMs: Signalling scissors in the tumour microenvironment. Nat Rev Cancer 8: 929-941.

Muschler J, Streuli CH. 2010. Cell-matrix interactions in mammary gland development and breast cancer. Cold Spring Harb Perspect Biol doi: 10.1101/ cshperspect.a003202.

Nagase H, Woessner JF Jr. 1999. Matrix metalloproteinases. J Biol Chem 274: 21491-21494.

Nasser N. 2008. Heparanase involvement in physiology and disease. Cell Mol Life Sci 65: 1706-1715.

Newman SA, Frenz DA, Tomasek JJ, Rabuzzi DD. 1985 Matrix-driven translocation of cells and nonliving particles. Science 228: 885-889.

Norton WHJ, Ledin J, Grandel H, Neumann CJ. 2005. HSPG synthesis by zebrafish Ext2 and Extl3 is required for Fgf10 signalling during limb development. Development 132: 4963-4973.

Olson MW, Gervasi DC, Mobashery S, Fridman R. 1997. Kinetic analysis of the binding of human matrix metalloproteinase-2 and -9 to tissue inhibitor of metalloproteinase (TIMP)-1 and TIMP-2. J Biol Chem 272: 29975-29983.

Orian-Rousseau V. 2010. CD44, a therapeutic target for metastasising tumours. Euro J Cancer 46: 1271-1277.

Ornitz DM, Marie PJ. 2002. FGF signaling pathways in endochondral and intramembranous bone development and human genetic disease. Genes Dev 16: 1446-1465.
Ozbek S, Balasubramanian PG, Chiquet-Ehrismann R, Tucker RP, Adams JC. 2010. The evolution of extracellular matrix. Mol Biol Cell 21: 4300-4305.

Page-McCaw A, Ewald AJ, Werb Z. 2007. Matrix metalloproteinases and the regulation of tissue remodelling. Nat Rev Mol Cell Biol 8: 221-233.

Paszek MJ, Zahir N, Johnson KR, Lakins JN, Rozenberg GI, Gefen A, Reinhart-King CA, Margulies SS, Dembo M, Boettiger D, et al. 2005. Tensional homeostasis and the malignant phenotype. Cancer Cell 8: 241-254.

Raffetto JD, Khalil RA. 2008. Matrix metalloproteinases and their inhibitors in vascular remodeling and vascular disease. Biochem Pharmacol 75: 346-359.

Raymond K, Deugnier MA, Faraldo MM, Glukhova MA. 2009. Adhesion within the stem cell niches. Curr Opin Cell Biol 21: 623-629.

Rebustini IT, Patel VN, Stewart JS, Layvey A, Georges-Labouesse E, Miner JH, Hoffman MP. 2007. Laminin alpha5 is necessary for submandibular gland epithelial morphogenesis and influences FGFR expression through betal integrin signaling. Dev Biol 308: 15-29.

Rebustini IT, Myers C, Lassiter KS, Surmak A, Szabova L, Holmbeck K, Pedchenko V, Hudson BG, Hoffman MP. 2009. MT2-MMP-dependent release of collagen IV $\mathrm{NC} 1$ domains regulates submandibular gland branching morphogenesis. Dev Cell 17: 482-493.

Reilly GC, Engler AJ. 2010. Intrinsic extracellular matrix properties regulate stem cell differentiation. J Biomech 43: $55-62$.

Rhodes JM, Simons M. 2007. The extracellular matrix and blood vessel formation: Not just a scaffold. J Cell Mol Med 11: 176-205.

Rosen SD, Lemjabbar-Alaoui H. 2010. Sulf-2: An extracellular modulator of cell signaling and a cancer target candidate. Expert Opin Ther Targets 14: 935-949.

Rozario T, DeSimone DW. 2010. The extracellular matrix in development and morphogenesis: A dynamic view. Dev Biol 341: 126-140.

Ruiz-Espejo F, Cabezas-Herrera J, Illana J, Campoy FJ, Munoz-Delgado E, Vidal CJ. 2003. Breast cancer metastasis alters acetylcholinesterase activity and the composition of enzyme forms in axillary lymph nodes. Breast Cancer Res Treat 80: 105-114.

Sakai T, Larsen M, Yamada KM. 2003. Fibronectin requirement in branching morphogenesis. Nature 423: 876881.

Schofield R. 1978. The relationship between the spleen colony-forming cell and the haemopoietic stem cell. Blood Cells 4: 7-25.

Schwartz MA. 2011. Integrins and extracellular matrix in mechanotransduction. Cold Spring Harb Perspect Biol 2: a005066.

Shakya R, Watanabe T, Costantini F. 2005. The role of GDNF/Ret signaling in ureteric bud cell fate and branching morphogenesis. Dev Cell 8: 65-74.

Shen Q, Wang Y, Kokovay E, Lin G, Chuang SM, Goderie SK, Roysam B, Temple S. 2008. Adult SVZ stem cells lie in a vascular niche: A quantitative analysis of niche cell-cell interactions. Cell Stem Cell 3: 289-300.

Sherman L, Wainwright D, Ponta H, Herrlich P. 1998. A splice variant of CD44 expressed in the apical ectodermal 
P. Lu et al.

ridge presents fibroblast growth factors to limb mesenchyme and is required for limb outgrowth. Genes Dev 12: $1058-1071$.

Shi Y, Massagué J. 2003. Mechanisms of TGF- $\beta$ signaling from cell membrane to the nucleus. Cell 113: 685-700.

Shiomi T, Lemaitre V, D’Armiento J, Okada Y. 2010. Matrix metalloproteinases, a disintegrin and metalloproteinases, and a disintegrin and metalloproteinases with thrombospondin motifs in non-neoplastic diseases. Pathol Int 60: 477-496.

Shook D, Keller R. 2003. Mechanisms, mechanics and function of epithelial-mesenchymal transitions in early development. Mech Dev 120: 1351-1383.

Silberstein GB, Daniel CW. 1982. Glycosaminoglycans in the basal lamina and extracellular matrix of the developing mouse mammary duct. Dev Biol 90: 215-222.

Smith HW, Marshall CJ. 2010. Regulation of cell signalling by uPAR. Nat Rev Mol Cell Biol 11: 23-36.

Sternlicht MD, Werb Z. 2001. How matrix metalloproteinases regulate cell behavior. Annu Rev Cell Dev Biol 17: 463-516.

Sternlicht MD, Lochter A, Sympson CJ, Huey B, Rougier JP, Gray JW, Pinkel D, Bissell MJ, Werb Z. 1999. The stromal proteinase MMP3/stromelysin-1 promotes mammary carcinogenesis. Cell 98: 137-146.

Sternlicht MD, Kouros-Mehr H, Lu P, Werb Z. 2006. Hormonal and local control of mammary branching morphogenesis. Differentiation 74: 365-381.

Sun X, Mariani FV, Martin GR. 2002. Functions of FGF signalling from the apical ectodermal ridge in limb development. Nature 418: 501-508.

Szabova L, Yamada SS, Birkedal-Hansen H, Holmbeck K. 2005. Expression pattern of four membrane-type matrix metalloproteinases in the normal and diseased mouse mammary gland. J Cell Physiol 205: 123-132.

Taddei I, Deugnier M-A, Faraldo MM, Petit V, Bouvard D, Medina D, Fassler R, Thiery JP, Glukhova MA. 2008. $\beta 1$ Integrin deletion from the basal compartment of the mammary epithelium affects stem cells. Nat Cell Biol 10: $716-722$.

Tanentzapf G, Devenport D, Godt D, Brown NH. 2007. Integrin-dependent anchoring of a stem-cell niche. Nat Cell Biol 9: 1413-1418.

ten Dijke P, Arthur HM. 2007. Extracellular control of TGFbeta signalling in vascular development and disease. Nat Rev Mol Cell Biol 8: 857-869.

Thiery JP, Acloque H, Huang RY, Nieto MA. 2009. Epithelial-mesenchymal transitions in development and disease. Cell 139: 871-890.
Vakonakis I, Campbell ID. 2007. Extracellular matrix: From atomic resolution to ultrastructure. Curr Opin Cell Biol 19: $578-583$.

Van den Steen PE, Opdenakker G, Wormald MR, Dwek RA, Rudd PM. 2001. Matrix remodelling enzymes, the protease cascade and glycosylation. Biochim Biophys Acta 1528: $61-73$.

van Hinsbergh VW, Koolwijk P. 2008. Endothelial sprouting and angiogenesis: Matrix metalloproteinases in the lead. Cardiovasc Res 78: 203-212.

Wang N, Tytell JD, Ingber DE. 2009a. Mechanotransduction at a distance: Mechanically coupling the extracellular matrix with the nucleus. Nat Rev Mol Cell Biol 10: 75-82.

Wang Q, Uhlirova M, Bohmann D. 2009b. Spatial restriction of FGF signaling by a matrix metalloprotease controls branching morphogenesis. Developmental Cell 18: 157-164.

Watanabe T, Costantini F. 2004. Real-time analysis of ureteric bud branching morphogenesis in vitro. Dev Biol 271: $98-108$.

Whittaker CA, Bergeron K-F, Whittle J, Brandhorst BP, Burke RD, Hynes RO. 2006. The echinoderm adhesome. Dev Biol 300: 252-266.

Wiseman BS, Sternlicht MD, Lund LR, Alexander CM, Mott J, Bissell MJ, Soloway P, Itohara S, Werb Z. 2003. Site-specific inductive and inhibitory activities of MMP-2 and MMP-3 orchestrate mammary gland branching morphogenesis. J Cell Biol 162: 1123-1133.

Wolfe JN. 1976. Risk for breast cancer development determined by mammographic parenchymal pattern. Cancer 37: 2486-2492.

Wyckoff JB, Wang Y, Lin EY, Li J-f, Goswami S, Stanley ER, Segall JE, Pollard JW, Condeelis J. 2007. Direct visualization of macrophage-assisted tumor cell intravasation in mammary tumors. Cancer Research 67: 2649-2656.

Xie T, Li L. 2007. Stem cells and their niche: An inseparable relationship. Development 134: 2001-2006.

Yamashita YM, Fuller MT, Jones DL. 2005. Signaling in stem cell niches: Lessons from the Drosophila germline. J Cell Sci 118: 665-672.

Yu H, Mouw JK, Weaver VM. 2010. Forcing form and function: Biomechanical regulation of tumor evolution. Trends Cell Biol 21: 47-56.

Zelzer E, Olsen BR. 2003. The genetic basis for skeletal diseases. Nature 423: 343-348.

Zimmermann DR, Dours-Zimmermann MT. 2008. Extracellular matrix of the central nervous system: From neglect to challenge. Histochem Cell Biol 130: 635-653. 


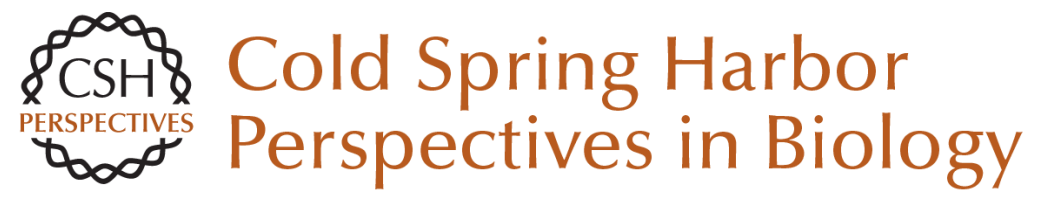

\title{
Extracellular Matrix Degradation and Remodeling in Development and Disease
}

\author{
Pengfei Lu, Ken Takai, Valerie M. Weaver and Zena Werb
}

Cold Spring Harb Perspect Biol 2011; doi: 10.1101/cshperspect.a005058 originally published online September 14, 2011

\section{Subject Collection Extracellular Matrix Biology}

Extracellular Matrix in Development: Insights from Mechanisms Conserved between Invertebrates and Vertebrates

Nicholas H. Brown

Extracellular Matrix Proteins in Hemostasis and Thrombosis Wolfgang Bergmeier and Richard O. Hynes

The Thrombospondins Josephine C. Adams and Jack Lawler

Cross Talk among TGF- $\beta$ Signaling Pathways, Integrins, and the Extracellular Matrix John S. Munger and Dean Sheppard

Heparan Sulfate Proteoglycans Stephane Sarrazin, William C. Lamanna and Jeffrey D. Esko

The Collagen Family Sylvie Ricard-Blum

Tenascins and the Importance of Adhesion Modulation Ruth Chiquet-Ehrismann and Richard P. Tucker Integrin Structure, Activation, and Interactions lain D. Campbell and Martin J. Humphries
Extracellular Matrix Degradation and Remodeling in Development and Disease

Pengfei Lu, Ken Takai, Valerie M. Weaver, et al.

Overview of the Matrisome--An Inventory of Extracellular Matrix Constituents and Functions Richard O. Hynes and Alexandra Naba

Integrins in Cell Migration Anna Huttenlocher and Alan Rick Horwitz

Fibronectins, Their Fibrillogenesis, and In Vivo Functions Jean E. Schwarzbauer and Douglas W. DeSimone

Extracellular Matrix: Functions in the Nervous System

Claudia S. Barros, Santos J. Franco and Ulrich Müller

Molecular Architecture and Function of Matrix Adhesions Benjamin Geiger and Kenneth M. Yamada

Cell-Extracellular Matrix Interactions in Normal and Diseased Skin

Fiona M. Watt and Hironobu Fujiwara

Genetic Analyses of Integrin Signaling Sara A. Wickström, Korana Radovanac and Reinhard Fässler

For additional articles in this collection, see http://cshperspectives.cshlp.org/cgi/collection/

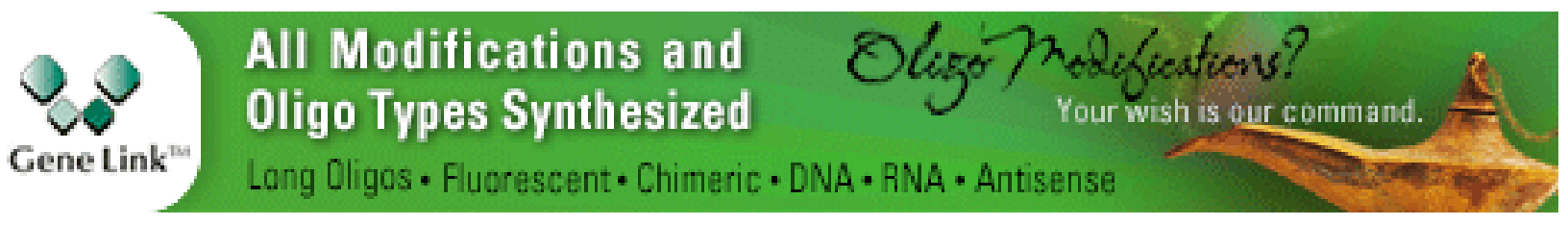

